\title{
Guidelines
}

Digestion

\section{Guidelines for Colonic Diverticular Bleeding and Colonic Diverticulitis: Japan Gastroenterological Association}

\author{
Naoyoshi Nagata a, ${ }^{a}$ Naoki Ishii ${ }^{a, c}$ Noriaki Manabe ${ }^{a, d}$ Kenji Tomizawa, e

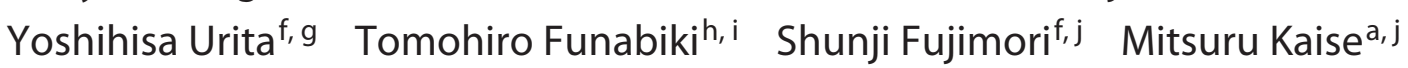 \\ a Japanese Gastroenterological Association, Tokyo, Japan; b Department of Gastroenterology and Hepatology, \\ National Center for Global Health and Medicine, Tokyo, Japan; ' Division of Gastroenterology, Tokyo Shinagawa \\ Hospital, Tokyo, Japan; d Division of Endoscopy and Ultrasonography, Department of Clinical Pathology and \\ Laboratory Medicine, Kawasaki Medical School General Medical Center, Okayama, Japan; 'Department of \\ Gastroenterological Surgery, Toranomon Hospital, Tokyo, Japan; fJapanese Society of Gastroenterology,Tokyo, \\ Japan; ${ }^{9}$ Department of General Medicine and Emergency Care, Toho University, School of Medicine, Tokyo, Japan; \\ h Japanese Society of Interventional Radiology, Saitama, Japan; 'Department of Emergency and Critical Care \\ Medicine, Saiseikai Yokohamashi Tobu Hospital, Yokohama, Japan; 'Department of Gastroenterology, Nippon \\ Medical School, Graduate School of Medicine, Tokyo, Japan
}

\section{Keywords}

Acute lower gastrointestinal bleeding - Acute colonic diverticulitis - Acute lower gastrointestinal hemorrhage . Clinical practice guideline $\cdot$ Colonic diverticular hemorrhage · Endoscopic management

\begin{abstract}
Colonic diverticular disease has been increasing in prevalence in Japan due to the rapidly aging population. Colonic diverticular bleeding can result in hemorrhagic shock requiring blood transfusion, and it carries a high risk of recurrence within 1 year. Colonic diverticulitis can cause abscess, fistula formation, and perforation of the colon that may require surgery, and it often recurs. As a result, patients with colonic diverticular disease are often bothered by required frequent examinations, re-hospitalization, and a consequent decrease in quality of life. However, the management of diver-
\end{abstract}

\section{KARGER}

E-Mail karger@karger.com www.karger.com/dig (c) 2019 Japanese Gastroenterological Association (JGA). Published by S. Karger AG, Basel

Karger Open access

This article is licensed under the Creative Commons AttributionNonCommercial-NoDerivatives 4.0 International License (CC BYNC-ND) (http://www.karger.com/Services/OpenAccessLicense). Usage and distribution for commercial purposes as well as any distribution of modified material requires written permission. ticular disease differs between Japan and Western countries. For example, computed tomography (CT) is readily accessible at Japanese hospitals, so urgent CT may be selected as the first diagnostic procedure for suspected diverticular disease. Endoscopic clipping or band ligation may be preferred as the first endoscopic procedure for diverticular bleeding. Administration of antibiotics and complete bowel rest may be considered as first-line therapy for colonic diverticulitis. In addition, diverticula occur mainly in the sigmoid colon in Western countries, whereas the right side or bilateral of the colon is more commonly involved in Japan. As such, diverticular disease in the right-side colon is more prevalent in Japan than in Western countries. Against this background, concern is growing about the management of colonic diverticular disease in Japan and there is currently no practice guideline available. To address this situation, the Japanese Gastroenterological Association decided to create a clinical guideline for colonic diverticular bleeding and colonic diver- 
ticulitis in collaboration with the Japanese Society of Gastroenterology, Japan Gastroenterological Endoscopy Society, and Japanese Society of Interventional Radiology. The steps taken to establish this guideline involved incorporating the concept of the GRADE system for rating clinical guidelines, developing clinical questions (CQs), accumulating evidence through a literature search and review, and developing the Statement and Explanation sections. This guideline includes 2CQs for colonic diverticulosis, 24 CQs for colonic diverticular bleeding, and 17 CQs for diverticulitis.

(c) 2019 Japanese Gastroenterological Association (JGA). Published by S. Karger AG, Basel

\section{Introduction}

In Japan, opportunities to treat patients with colonic diverticular disease (diverticular bleeding and diverticulitis) have been increasing in recent years as the prevalence of colonic diverticula has increased $[1,2]$. In particular, the number of reports of colonic diverticular bleeding from Japan has been increasing in the past 2 or 3 years [3-21]. Colonic diverticular bleeding and diverticulitis are both acute illnesses, but because they tend to recur and necessitate colectomy when severe, their clinical significance is increasing. Novel treatment methods such as endoscopic band ligation (EBL) have been introduced as hemostatic modalities for colonic diverticular bleeding, and the knowledge and skills required for the diagnosis and treatment of colonic diverticular disease have steadily accumulated $[3,14]$. However, challenges remain, including a low rate of identifying bleeding sites [22] and a relatively high rate of rebleeding after achieving hemostasis [14, 17, 23]. Against this background, momentum has grown to establish a clinical practice guideline, prompting the Japanese Gastroenterological Association to begin development in collaboration with the Japanese Society of Gastroenterology, Japan Gastroenterological Endoscopy Society, and Japanese Society of Interventional Radiology.

Members of the guideline committee were selected in early 2016, and policies for and scheduling of the development process were finalized in May 2016. Diverticular bleeding and diverticulitis of the colon were chosen as the target illnesses of the guideline. Because treatment for colonic diverticular bleeding begins with a diagnosis of acute lower gastrointestinal (GI) bleeding (LGIB), it was decided to create several clinical questions (CQs) related to the treatment of LGIB. The steps taken to establish the guideline involved incorporating the concept of the
GRADE system for rating clinical guidelines, developing the CQs, accumulating evidence through a literature search and review, and developing the Statement and Explanation sections. A total of 9 guideline committee sessions were held to facilitate constructive discussion about the guideline before the first draft was developed. This draft was then revised by an external assessment committee in June 2017 and made available for public comment in July 2017. Input and feedback received from the Japan Society of Coloproctology were particularly valuable. After revisions, the Guideline for Colonic Diverticular Bleeding and Colonic Diverticulitis in Japan (hereinafter, the Guideline) was finalized. The Guideline was published in Japanese in 2017.

\section{Developing the Guideline}

\section{Collecting the Evidence}

Academic articles were screened and extracted using keywords specific to each CQ and the online database search engines PubMed/Medline and Igaku Chuo Zasshi Web. Extracted articles were subjected to primary and secondary screenings. Most articles that are cited in the Guideline were published between 1995 and 2016, but important articles are cited regardless of publication date. Some articles that were not extracted in the literature search but were deemed necessary to cite in the Guideline were obtained through hand-searching.

\section{Evaluating the Overall Evidence}

Evaluating the Articles

Articles selected for use in the Guideline were classified based on study design (meta-analyses, randomized trials and non-randomized controlled studies, cohort studies, case-control studies, cross-sectional studies, case series, guidelines, or systematic reviews). For each article, a structured abstract was developed that included the study outcomes, limitations, and conclusion. Risk of bias (selection, execution, detection, and attrition biases) was evaluated according to the Minds Handbook for Clinical Practice Guideline Development.

Defining the Quality of Evidence

Overall evidence was evaluated based on all articles cited for each CQ and was rated A-D (Table 1) [24].

Defining the Strength of Recommendation

Strength of recommendation is defined in Table 2. Decisions were made upon agreement among committee 
Table 1. Quality of evidence

High: it is certain that the estimate of effect is virtually identical to the actual effect A

Moderate: confidence in the estimate of effect is moderate

$\mathrm{B}$

Low: confidence in the estimate of effect is limited

B

Very low: the estimate of effect is quite uncertain

$\mathrm{D}$

members after careful consideration of the (i) quality of evidence and (ii) balance of benefits and harms (balance between disadvantages such as patient burden, cost, and benefits acquired by implementing recommended practice).

\section{Management of Colonic Diverticular Bleeding}

A flowchart for the diagnosis and treatment of diverticular bleeding is shown in Figure 1. Diverticular bleeding typically presents as acute-onset painless hematochezia. In addition to taking medication history, physical examination, and blood testing, fluid replacement and blood transfusion are performed when necessary to stabilize vital signs (CQ4-7). When patients with upper GI bleeding have a large amount of bleeding, acute-onset hematochezia becomes the main symptom, necessitating differential diagnosis. At this time, it is important to insert a gastric tube or perform upper GI endoscopy prior to colonoscopy (CQ5).

Colonoscopy is subsequently performed, but in some patients with acute LGIB, abdominal computed tomography $(\mathrm{CT})$ may be considered (CQ8,9). For colonoscopy, it is important to pay attention to bowel preparation (with oral lavage solution), colonoscopy start time (within or after $24 \mathrm{~h}$ ), and endoscopic equipment (e.g., endoscopes with water-jet system), and efforts should be made to identify the source of bleeding and make an accurate diagnosis (CQ10-14).

Endoscopic hemostasis is performed when stigmata of recent hemorrhage (SRH) are identified (CQ15,16). Most colonic diverticula are false diverticula that do not have muscularis propria, and effective endoscopic therapy should be selected after considering the anatomical characteristics of the colonic diverticula and vasa recta.

Arterial embolization or colectomy is performed when endoscopic hemostasis is unsuccessful (CQ17-21). Treatment should be selected after considering indications, invasion, treatment efficacy, and unexpected complications.

Diverticular Disease Guideline
Table 2. Strength of recommendation

\begin{tabular}{ll}
\hline Implementation is recommended & Do it \\
Implementation is proposed & Probably do it \\
Implementation is not proposed & Probably don't do it \\
Implementation is not recommended & Don't do it \\
\hline
\end{tabular}

It is important to pay attention to preventing recurrence because colonic diverticular bleeding has a high risk of recurrence over a long-term follow-up period (CQ22-26).

\section{Management of Colonic Diverticulitis}

A flowchart for the diagnosis and treatment of patients with fever or acute abdominal pain indicative of colonic diverticulitis is shown in Figure 2.

Physical examination and blood testing are performed first, and an imaging test (CT or ultrasonography [US]) is performed additionally when it is necessary to examine for complications such as abscess, perforation, and peritonitis (CQ27-30).

Follow-up observation is carried out after antibiotic therapy and bowel rest when colonic diverticulitis is not accompanied by abscess or perforation (CQ31-33).

Even when colonic diverticulitis is accompanied by abscess or perforation, conservative treatment is carried out if the site of peritonitis is limited to the local area. At present, there are no clear criteria related to abscess size as an indication for US- or CT-guided drainage, but antibiotic therapy and bowel rest are recommended when abscess size is $\leq 3 \mathrm{~cm}$ (CQ36). When the abscess is $\geq 5 \mathrm{~cm}$, US- or CT-guided drainage is recommended in addition to antibiotic therapy and bowel rest (CQ36). However, when the abscess is $3-5 \mathrm{~cm}$, the treatment approach is tailored to individual patients after carefully considering the pathological condition and feasibility of drainage depending on the availability of human and facility resources. Patients unresponsive to drainage need to be placed under strict follow-up observation with the possibility of colectomy. 
Fig. 1. Flowchart for the diagnosis and treatment of colonic diverticular bleeding. GI, gastrointestinal; CT, computed tomography; $\mathrm{SRH}$, stigmata of recent hemorrhage.

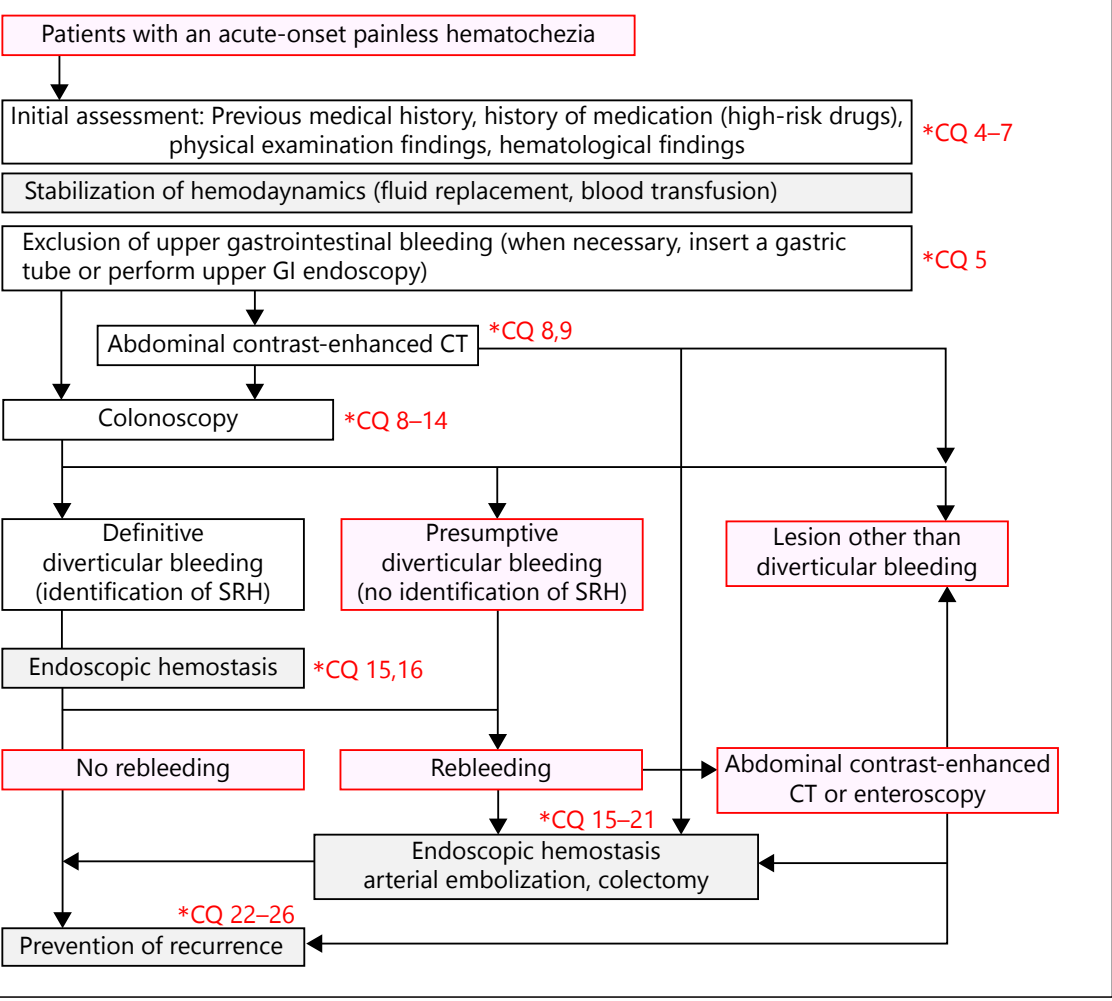

In contrast, patients with generalized, not localized, peritonitis are indicated for emergency surgery (CQ35).

The recurrence of diverticulitis is not necessarily an indicator of poor prognosis (CQ41). In principle, conservative treatment is recommended for recurrent diverticulitis without abscess or perforation. Even though colectomy is not indicated for recurrent diverticulitis alone $(\mathrm{CQ} 34,37)$, it is indicated for patients who have multiple recurrence, intestinal stricture, or fistula in, for example, the bladder (CQ38, 39).

Effective methods to prevention recurrence are currently not supported by high-quality evidence and thus require further investigation (CQ43).

\section{Epidemiology of Diverticula in the Colon}

CQ1: Is the prevalence of colonic diverticula higher in Japan than that in the West?

Statement: The prevalence of colonic diverticula is lower in Japan than that in the West.

Quality of evidence: C

Explanation

Colonic diverticulosis is common in the West, with a prevalence of $\geq 50 \%$ among individuals aged $\geq 60$ years. In an American study, 28\% of individuals with a mean age of 55 years had $\geq 3$ diverticula, $32 \%$ had $1-2$, and $40 \%$ had 0 , for an overall prevalence of $60 \%$ [25]. Another study of individuals with a mean age of 55 years showed the prevalence of diverticula was $42 \%$ [26]. According to statistics published during 2001-2010 in Japan, the prevalence of colonic diverticula in individuals with a mean age of 52 years was $23.9 \%$ [2]. These findings indicate that the proportion of individuals with colonic diverticula is lower in Japan than that in the West.

CQ2: Does the frequency of colonic diverticula vary by site in the colon?

Statement: Many Japanese patients have diverticula on the right side of the colon, but the proportion of diverticula on the left side increases with age. Conversely, Caucasians in the United States often have diverticula on the left side of the colon.

\section{Quality of evidence: B}

\section{Explanation}

Among Japanese patients with colonic diverticula who are $<50$ years of age, $75 \%$ of diverticula are on the right side of the colon. However, the incidence of colonic diverticula on the left side increases with age to the point where $60 \%$ of patients aged $\geq 70$ years have diverticula on 


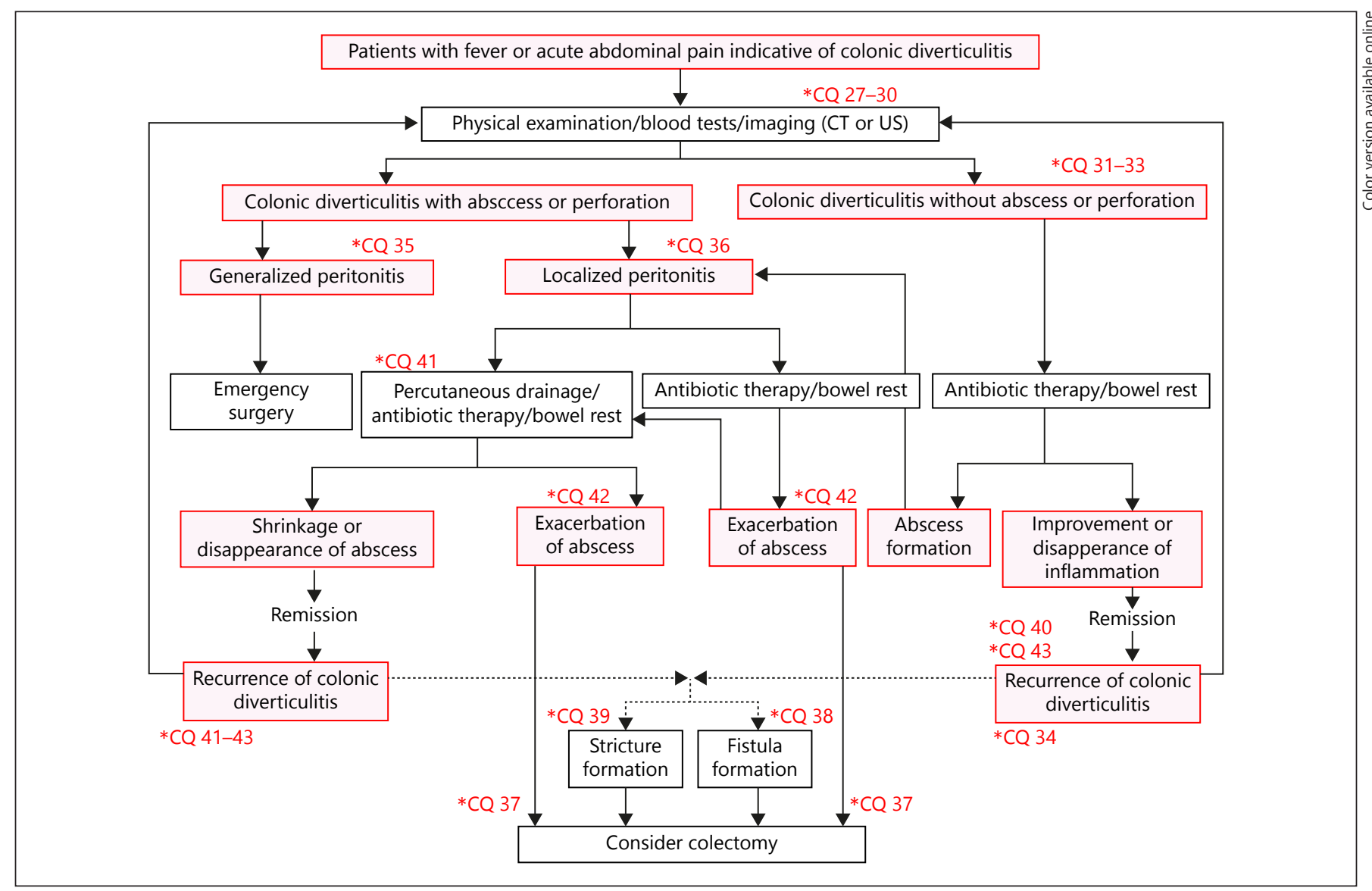

Fig. 2. Flowchart for the diagnosis and treatment of colonic diverticulitis. CT, computed tomography; US, ultrasonography.

the left side of the colon, with $25 \%$ of these patients having colonic diverticula only on the left side of the colon $[2,27,28]$. In the United States, $80 \%$ of colonic diverticula occur on the left side including $70 \%$ occurring in the sigmoid colon, which account for the majority of colonic diverticula. However, incidence varies by race in the United States, and Caucasian populations have a high incidence of diverticula in the sigmoid colon [26], suggesting that the anatomical side of colonic diverticula varies with race.

\section{Epidemiology of Colonic Diverticular Bleeding}

CQ3: What is the long-term recurrence rate of colonic diverticular bleeding after achieving hemostasis?

Statement: The 1- and 2-year recurrence rates of colonic diverticular bleeding are $20-35 \%$ and $33-42 \%$, respectively, in Japan.

Quality of evidence: C

Diverticular Disease Guideline

\section{Explanation}

Only a few studies have reported the long-term rates of rebleeding in colonic diverticular bleeding. In Japan, 3 retrospective cohort studies have investigated the long-term rates of rebleeding among patients admitted for treatment of colonic diverticular bleeding in whom hemostasis was achieved after conservative treatment, endoscopic therapy, or arterial embolization; the 1-year rebleeding rate was $20-35 \%$ and 2 -year rebleeding rate was $33-42 \%$ [29-31]. In a retrospective cohort study conducted in the United States, the 1- and 2-year rebleeding rates of colonic diverticular bleeding were 30 and $40 \%$, respectively, among patients in whom hemostasis was achieved after treatment other than surgery [32], which are results comparable to those of the Japanese studies. In contrast, a prospective cohort study conducted in France showed that the 1-, 5-, and 10-year rebleeding rates were $3.8,6.9$, and $9.8 \%$ [33], respectively, which are extremely low compared with the abovementioned studies. 


\section{Diagnosis and Treatment of Colonic Diverticular Bleeding}

CQ4: What should be the focus of management for patients who present with presumed acute LGIB or colonic diverticular bleeding in an initial clinical assessment?

Statement: In an initial clinical assessment, it is important to assess vital signs such as disturbance of consciousness, blood pressure, and heart rate and to stabilize hemodynamics while concurrently assessing accompanying symptoms, comorbidities, medication history, and blood tests.

Quality of evidence: C

Strength of recommendation: Do it

Agreement rate: $100 \%$

\section{Explanation}

In the initial assessment, the state of consciousness (lightheadedness) and hemodynamics such as blood pressure and heart rate should be assessed when patients present with presumed LGIB or colonic diverticular bleeding [34]. It is possible to predict the severity of bleeding and determine the indication for fluid resuscitation or blood transfusion [34]. When initial assessment shows abnormal findings in the vital signs, it is important that the patient be monitored, administered oxygen, and given an infusion. While stabilizing hemodynamics, accompanying symptoms, comorbidity, medication history, and blood test results should be evaluated [34]. Evaluating accompanying symptoms will be useful for the differentiation of LGIB. Patients with colonic diverticular bleeding often have indolent hematochezia [34], but when they have diarrhea and abdominal pain as well, the possibility of enteritis such as ischemic colitis and inflammatory bowel disease increases [34], and if patients have fever as well, the likelihood of developing infectious enteritis increases. Thus, obtaining a thorough medication history, such as anticoagulants, antiplatelets, and nonsteroidal anti-inflammatory drugs (NSAIDs), is important for predicting the risk of rebleeding and thromboembolism and for overall management during and after hospital admission. Furthermore, comorbidities (e.g., chronic kidney disease, cirrhosis, hypertension, diabetes, and dyslipidemia), previous medication history, blood tests (e.g., hemoglobin, hematocrit $[\mathrm{Ht}]$, prothrombin timeinternational normalized ratio, blood urea nitrogen [BUN], and creatinine [Cr]) are useful in determining indication for admission, intensive care, and timing of tests [34].
CQ5: What effectively differentiates lower and upper GI bleeding?

Statement: In patients with severe hematochezia, upper GI bleeding should be excluded by calculating the BUN-to-Cr ratio (BUN:Cr) and inserting a nasogastric tube or performing upper GI endoscopy.

Quality of evidence: $B$

Strength of recommendation: Do it

Agreement rate: $100 \%$

Explanation

GI bleeding is suspected from a history of hematemesis and black, dark red, or bright red stool. In general, the first 2 indicate upper GI bleeding and the last 2 indicate LGIB. However, patients with upper GI bleeding sometimes experience a large amount of dark or bright red stool [34-36]. In a randomized controlled study, 13 of 85 patients (15.3\%) with multiple episodes of severe hematochezia had upper GI bleeding [34-36]. In another randomized controlled study, 4 of 112 patients (3.6\%) with severe hematochezia had upper GI bleeding [35]. According to a meta-analysis, clinical findings indicating upper GI bleeding are black stool, bloody or coffee grounds aspirate from the nasogastric tube, and BUN:Cr $\geq 30$ [37]. Therefore, in patients with severe dark or bright red stool, upper GI bleeding needs to be ruled out by calculating BUN:Cr and inserting a nasogastric tube or performing upper GI endoscopy.

CQ6: What risk factors predict continuous bleeding or rebleeding in patients with acute LGIB or colonic diverticular bleeding?

Statement: Signs and symptoms of shock, symptoms accompanying hematochezia, medication history, and hematological findings at initial examination are predictors of continuous bleeding or rebleeding.

Quality of evidence: C

Strength of recommendation: Probably do it

Agreement rate: $100 \%$

Explanation

Patients with acute LGIB or colonic diverticular bleeding occasionally have continuous bleeding or rebleeding after hospital admission [38-43] and may require blood transfusion, arterial embolization, or colectomy $[40,43]$. If these patients could be stratified at initial examination, it would help physicians decide on the indication for hospitalization, the timing of treatment, and the provision of intensive care services. However, unlike acute upper GI bleeding, only 8 studies have developed models that predict continuous bleeding, rebleeding, and mortality in patients with LGIB [38-45], 
Table 3. Predictive models with validation for severe bleeding risk in patients with acute LGIB

\begin{tabular}{|c|c|c|c|c|c|}
\hline Study design & Subjects & Clinical outcomes & Predictors & ROC-AUC & Validation \\
\hline $\begin{array}{l}\text { Retrospective } \\
\text { cohort } \\
\text { study [38] }\end{array}$ & $\begin{array}{l}\text { Patients } \\
\text { hospitalized } \\
\text { with acute LGIB } \\
(n=252)\end{array}$ & $\begin{array}{l}\text { Severe bleeding } \\
\text { (continuous or } \\
\text { rebleeding) }\end{array}$ & $\begin{array}{l}\text { Heart rate }>100 \text {, systolic blood pressure } \\
<115 \mathrm{~mm} \mathrm{Hg} \text {, loss of consciousness, } \\
\text { no-abdominal pain, rectal bleeding within } \\
4 \text { h, aspirin use, and comorbidities }>2\end{array}$ & 0.76 & $\begin{array}{l}\text { External validation } \\
\text { with prospective } \\
\text { study }(n=275, \\
\text { ROC-AUC 0.75) }[40]\end{array}$ \\
\hline $\begin{array}{l}\text { Retrospective } \\
\text { cohort } \\
\text { study [45] }\end{array}$ & $\begin{array}{l}\text { Patients } \\
\text { hospitalized } \\
\text { with acute LGIB } \\
(n=332)\end{array}$ & $\begin{array}{l}\text { Death, rebleeding, } \\
\text { hemostatic procedures } \\
\text { (endoscopy, colorectal } \\
\text { surgery, arterial } \\
\text { embolization) }\end{array}$ & $\begin{array}{l}\text { Male, comorbidities (cardiovascular } \\
\text { disease, dementia), past-history of } \\
\text { diverticular bleeding, or angioectasia, } \\
\text { presence of orthostatic symptoms, } \\
\text { history of bright red hematochezia, } \\
\text { systolic blood pressure }<100 \mathrm{~mm} \mathrm{Hg} \text {, } \\
\text { Hematocrit }<30 \% \text {, and creatinine } \\
>133 \mu \mathrm{mol} / \mathrm{L}\end{array}$ & $\begin{array}{l}0.92 \text { (death), } \\
0.93 \text { (rebleeding), } \\
0.95 \text { (procedure } \\
\text { needed) }\end{array}$ & $\begin{array}{l}\text { Internal validation } \\
(n=190), \text { and } \\
\text { external validation } \\
(n=142)\end{array}$ \\
\hline $\begin{array}{l}\text { Retrospective } \\
\text { and prospective } \\
\text { cohort } \\
\text { study [43] }\end{array}$ & $\begin{array}{l}\text { Patients } \\
\text { hospitalized } \\
\text { with acute LGIB } \\
(n=600)\end{array}$ & $\begin{array}{l}\text { Severe bleeding } \\
\text { (continuous or } \\
\text { rebleeding) }\end{array}$ & $\begin{array}{l}\text { NSAIDs use, non-aspirin antiplatelet } \\
\text { use, no-diarrhea, no-abdominal pain, } \\
\text { systolic blood pressure }<100 \mathrm{~mm} \mathrm{Hg} \text {, } \\
\text { and Alb }<3.0 \mathrm{~g} / \mathrm{dL}\end{array}$ & 0.77 & $\begin{array}{l}\text { Internal validation } \\
\text { with prospective } \\
\text { study }(n=161 \\
\text { ROC-AUC } 0.76)\end{array}$ \\
\hline
\end{tabular}

LGIB, lower gastrointestinal bleeding; ROC-AUC, receiver operating characteristic/area under the curve; NSAIDs, non-steroidal anti-inflammatory drugs.

of which only 3 studies have verified the validity of the prediction model $[38,43,45]$ (Table 3). The important predictors of continuous bleeding or rebleeding are hypotension, tachycardia, signs and symptoms of shock such as loss of consciousness, symptoms accompanying hematochezia (bright red stool without abdominal pain or diarrhea), medication history (antiplatelets and NSAIDs such as aspirin), past medical history (colonic diverticula or angiodysplasia), comorbidities $(\geq 2)$, and hematological findings such as $\mathrm{Ht}, \mathrm{Cr}$, and albumin (Alb) levels [38, 43, 45]. However, to generalize these factors, more evidence needs to be accumulated because the area under the receiver operating characteristic curve indicating the predicting power was $\leq 0.8$ in those studies that investigated validity.

CQ7: Is the discontinuation of antithrombotic drugs recommended for patients with acute LGIB or colonic diverticular bleeding after hospital admission?

Statement: The risk of thromboembolism due to discontinuation of antithrombotic drugs and the risk of bleeding due to continuation varies among patients. Therefore, all physicians involved in the management of such patients should cooperate with each other and establish a medication management plan tailored to individual patients. However, it is recommended that low-dose aspirin for primary prevention of cardiovascular events be discontinued.

Quality of evidence: C

Strength of recommendation: Probably do it
Agreement rate: $88 \%$

\section{Explanation}

Post-admission management is essential because of the association between discontinuation of antithrombogenic drugs and risk of thromboembolism or subsequent death [46-51]. A common recommendation among preexisting guidelines [34,52-57] is that drugs should be discontinued after dialogue and in close collaboration with experts in different fields such as hematologists, cardiologists, neurologists, and gastroenterologists.

The clinical practice guidelines for LGIB published in the United States and Europe recommend temporary discontinuation of anticoagulants because of the potential risk of bleeding [34]. However, discontinuation of antithrombogenic drugs increases the risk of thromboembolism in patients on anticoagulants or antiplatelets and at increased risk of thromboembolic events [34, 5257]. In the present Guideline, recommendations with a uniform approach for discontinuing antithrombogenic drugs are generally avoided. Instead, the Guideline recommends that all involved physicians cooperate to establish a medication management plan tailored to individual patients on antithrombogenic drugs because of individual variability in the risk of thromboembolism due to drug discontinuation and in the risk of bleeding due to drug continuation. However, the discontinuation of low-dose aspirin for primary prevention is recommended because the risk of thromboembolism outweighs the risk of bleeding. 
CQ8: What is the optimal initial diagnostic modality for identifying the source of bleeding in patients presenting with presumed acute LGIB or colonic diverticular bleeding?

Statement: Colonoscopy is recommended as an initial diagnostic modality when acute LGIB or colonic diverticular bleeding is suspected.

Quality of evidence: C

Strength of recommendation: Do it

Agreement rate: $100 \%$

Explanation

Colonoscopy [58-64], CT, angiography, scintigraphy [59-61, 64, 65], and abdominal US [66] are commonly used for the diagnosis of acute LGIB and colonic diverticular bleeding. These modalities have been compared in observational studies [59-61, 64] but not in a randomized controlled study. Due to recent technological advances in medical devices, CT is becoming a popular diagnostic modality for acute LGIB. According to a meta-analysis, the diagnostic accuracy of CT angiography in acute GI bleeding was $85.2 \%$ sensitivity (95\% CI $75.5-91.5)$ and $92.1 \%$ specificity (95\% CI 76.7-97.7), showing excellent accuracy [65]. Also, in a cross-sectional study on performing CT angiography after colonoscopy, the accuracy of diagnosing the site of bleeding, and thus the lesion, was higher with CT angiography than with colonoscopy [59]. In colonoscopy, the accuracy of diagnosing the source of bleeding ranges from 52.9 to $91 \%[59,60,63,64]$. However, unlike CT angiography and scintigraphy, colonoscopy enables treatment directly after diagnosis [58, 60, 63-65]. Moreover, a case-control study comparing colonoscopy with angiography and scintigraphy [60] and case series $[61,64]$ have shown high rates of diagnosis and treatment with low medical costs in the colonoscopy group. Based on these findings, colonoscopy is recommended as an initial diagnostic modality in patients presenting with presumed acute LGIB or colonic diverticular bleeding. CT angiography is associated with radiation exposure and contrast nephropathy, but it can be an initial diagnostic choice when colonoscopy cannot readily be performed due to facility regulations or when patients with LGIB are intolerant to bowel preparation or examination itself $[60,65]$. Abdominal US has a lower diagnostic rate than that of colonoscopy, but because it does not require bowel preparation and is not associated with radiation exposure, this modality may be selected as an auxiliary diagnostic method to be used before colonoscopy [66].
CQ9: Is contrast enhanced (CE)-CT prior to colonoscopy effective for acute LGIB and colonic diverticular bleeding?

Statement: Due to insufficient evidence, CE-CT prior to colonoscopy is not recommended for all patients with acute LGIB or colonic diverticular bleeding. It has been proposed that CE-CT should be performed according to the current status of patients and facilities.

Quality of evidence: C

Strength of recommendation: Probably do it

Agreement rate: $75 \%$

Explanation

Three retrospective observational studies [67-69] and one prospective observational study [70] have investigated whether pre-colonoscopy CE-CT improves the rate of identifying the source of bleeding and the diverticula with SRH in patients presenting with acute LGIB or colonic diverticular bleeding, showing a low rate of positive extravasation (15-36\%) and a low sensitivity (20-52\%) on CE-CT [67-70]. Conversely, bleeding diverticula were identified on colonoscopy in $60-68 \%$ of patients with extravasation on CE-CT (positive predictive value) and $20-31 \%$ of those without extravasation, demonstrating a higher identification rate in the former $[67,69]$. In one of the retrospective observational studies, CE-CT significantly improved the rate of identifying vascular lesions ( 35.7 vs. $20.6 \% ; p=0.01$ ) and the rate of providing endoscopic therapy (34.9 vs. $13.4 \% ; p<0.01$ ), with a high rate of agreement regarding the source of bleeding between CE-CT and colonoscopy ( $\kappa$ value: $0.83 ; p<0.01$ ) [68]. On the other hand, in the cross-sectional study [70], the positive rate of extravasation on CE-CT was not high, at $15.4 \%(8 / 52)$, and thus the application of CE-CT for all patients is not recommended. Although the difference is not significant, the rate of extravasation is high when CE-CT is performed within $2 \mathrm{~h}$ of the last episode of hematochezia $(p=0.123)$, suggesting that CE-CT may be indicated for acute LGIB and colonic diverticular bleeding for these patients.

CQ10: Is it effective to perform colonoscopy for acute LGIB within $24 \mathrm{~h}$ of a hospital visit?

Statement: It is proposed that colonoscopy be performed within $24 \mathrm{~h}$ to identify the source of bleeding and as a therapeutic intervention.

Quality of evidence: B

Strength of recommendation: Probably do it

Agreement rate: $100 \%$

Explanation

Three studies have involved a meta-analysis of patients with acute LGIB who underwent colonoscopy in the ear- 
ly phase and those who waited some interval before undergoing colonoscopy [71-73]. Two of these 3 studies included 2 randomized controlled studies [35, 36], 4 observational studies, and 1 retrospective cohort study that involved propensity score matching [74] and the results revealed a significantly higher rate of identifying the source of bleeding in the early colonoscopy group, with no significant difference in rebleeding rate, in-hospital mortality, or rate of transition to surgery $[71,72]$. In contrast, the third study that included 2 randomized controlled studies and 10 observational studies found that the rate of performing endoscopic therapy was significantly higher in the early colonoscopy group, with no significant difference in the rate of identifying the source of bleeding, unexpected complications, rebleeding, blood transfusion, or death [73]. Although insignificant, the early colonoscopy group had a shorter hospital stay and lower overall medical cost. However, 2 randomized controlled studies had a small sample size, with a possibility of a type II error $[35,36]$. One of the studies also included randomized patients treated between 1993 and 1995, when the utility of endoscopic hemostasis for acute LGIB had not been established [35]. Therefore, it is necessary to perform a randomized controlled study with a sample size large enough to address the question "Is it effective to perform colonoscopy within $24 \mathrm{~h}$ of hospital visit?" Until then, it remains unclear as to whether the primary outcome can be improved, but it is proposed that colonoscopy be performed in the early phase, if possible, to also facilitate triage.

CQ11: Is bowel preparation with an oral lavage solution effective for colonoscopy for acute LGIB and colonic diverticular bleeding?

Statement: Bowel preparation with an oral lavage solution is recommended, except for patients with contraindications.

Quality of evidence: C

Strength of recommendation: Do it

Agreement rate: 100\%

\section{Explanation}

The purpose of colonoscopy in patients with acute LGIB and colonic diverticular bleeding is to provide accurate diagnosis and proper treatment. For this, bowel preparation is important to ensure the safety of colonoscopy and a high success rate of reaching the cecum. The frequencies of unexpected adverse events attributable to oral lavage agents do not differ significantly between acute LGIB and non-GI bleeding [75], and bowel preparation has been shown to facilitate the accurate diagnosis of disease and SRH (see CQ13) and enable endoscopic treatment [62]. On the other hand, the rate of reaching the cecum was not high, in the range of $20-70 \%$, among patients who had colonoscopy in the early phase without bowel preparation with oral lavage solution [76-79], and $6.4 \%$ of the patients $(22 / 345)$ developed fever after colonoscopy [79]. Two retrospective observational studies have investigated the difference in cecal intubation rates between bowel preparation with oral lavage solutions and other bowel preparation methods (e.g., enema) $[76,78]$ and reported a higher rate with the former [76, 78]. Use of other bowel preparation methods (without using oral lavage solutions) is acceptable and bowel preparation itself can be eliminated in patients with post-polypectomy bleeding or rectal ulcer in which bleeding sources can be anticipated before colonoscopy. Otherwise, bowel preparation with oral lavage solutions is recommended.

CQ12: Is total colonoscopy effective for acute LGIB and colonic diverticular bleeding?

Statement: Colonic diverticular bleeding is the leading cause of acute LGIB. Therefore, it is recommended that total colonoscopy covering the terminal ileum be performed.

Quality of evidence: C

Strength of recommendation: Do it

Agreement rate: $100 \%$

Explanation

No previous studies have compared sigmoidoscopy and total colonoscopy in diagnostic and endoscopic therapy for acute LGIB or colonic diverticular bleeding. Colonic diverticular bleeding is the leading cause of acute LGIB $[62,68,80]$. In patients with colonic diverticular bleeding, diverticula with SRH (see CQ13) are often detected on the right side of the colon [80], and although rare, hemorrhagic lesions are observed in the terminal ileum from time to time [81]. Therefore, we recommend total colonoscopy encompassing the terminal ileum. Acute rectal ulcer, ischemic enteritis, and tumors are also included in clinical cases of acute LGIB $[62,68,80]$. But these do not necessarily require total colonoscopy in emergency situations.

CQ13: What endoscopic findings of colonic diverticular bleeding are indications for endoscopic hemostasis?

Statement: The following are defined as SRH: (i) active bleeding; (ii) non-bleeding visible vessels; and (iii) adherent clot underlying (i) or (ii). Endoscopic hemostasis is recommended for a colonic diverticulum with SRH. 

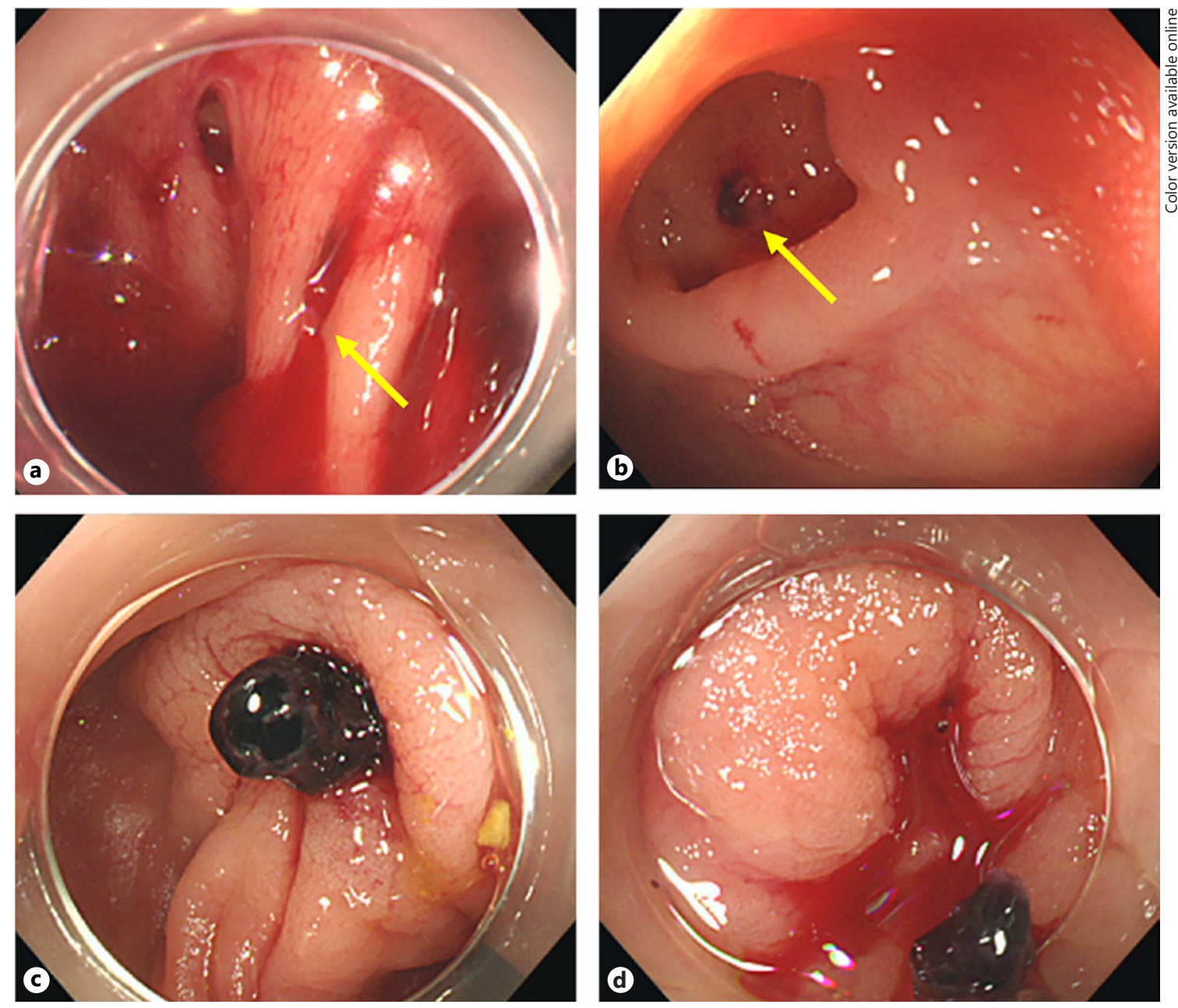

Fig. 3. Stigmata of recent hemorrhage (SRH) of a diverticulum. a Active bleeding at the neck of a diverticulum (arrow). b Nonbleeding visible vessel at the base of a diverticulum (arrow). c Ad- herent clot. d Active bleeding caused by removal of an adherent clot. Active bleeding or a non-bleeding visible vessel is generally observed when a clot with the appearance of SRH is removed.

\section{Quality of evidence: C \\ Strength of recommendation: Do it \\ Agreement rate: $100 \%$ Explanation}

Active bleeding (Fig. 3a), non-bleeding visible vessels (Fig. 3b), and adherent clots (Fig. 3c, d) that develop into active bleeding or non-bleeding visible vessels upon removal of clots are defined as SRH [82]. Definitive colonic diverticular bleeding is defined as colonoscopic visualization of colonic diverticulum with SRH. Presumptive diagnosis is based on fresh blood localized to colonic diverticula in the presence of a potential bleeding source on complete colonoscopy; or bright red blood per rectum confirmed by colonoscopy that demonstrates a single potential bleeding source in the colon, complemented by negative upper endoscopy or negative capsule endoscopy, or negative nasogastric tube. Previous cohort studies of patients with definitive diverticular bleeding $[62,82]$ have shown a high rate (53-66\%) of early rebleeding $(\leq 30$ days of treatment) in patients who underwent conservative therapy alone, but the rate decreased with endoscopic hemostasis. Also, in a prospective cohort study [62], early rebleeding ( $\leq 30$ days) did not occur after conservative treatment without endoscopic hemostasis in patients with black or dark red flat spots in colonic diverticula that did not appear to be visible vessels or in patients whose colonic diverticula were clean when clots were removed. Based on these findings, endoscopic hemostasis is recommended for colonic diverticula with SRH such as active bleeding, non-bleeding visible vessels, and adherent clots. 
CQ14: Are there any innovative and effective endoscopic tools for identifying the source of bleeding in acute LGIB and colonic diverticular bleeding?

Statement: The use of endoscopic distal attachments and endoscopes with a water-jet system is proposed.

Quality of evidence: C

Strength of recommendation: Probably do it

Agreement rate: $100 \%$

Explanation

Because a colonic diverticulum with SRH (definitive colonic diverticular bleeding) is associated with a high incidence of rebleeding, it is important to identify SRH and perform endoscopic hemostasis. However, only a small number of studies have investigated factors that improve the identification of SRH [22]. In a study conducted by Niikura et al. [22], the identification of SRH was improved by colonoscopy (i) when performed within 24 h, (ii) by expert endoscopists who have performed $>1,000$ colonoscopies, and (iii) with the use of disposable distal attachments and water-jet systems. Although the primary treatment outcome was not to improve the identification rate of SRH in the studies, other studies have also reported that bowel preparation with oral lavage solutions and colonoscopy performed within $24 \mathrm{~h}$ improve the identification rate of SRH $[35,71,74,76,83]$.

CQ15: What hemostatic methods are available for endoscopy? Is there any difference in effectiveness among them?

Statement: There are several endoscopic hemostatic methods including epinephrine injection, coagulation, clipping, and ligation (EBL and detachable snare ligation), among which ligation is less frequently associated with transition to arterial embolization and surgery, suggesting that it is more effective than the other methods.

Quality of evidence: C

\section{Explanation}

Colonic diverticular bleeding generally occurs at the base or neck of diverticula due to damage to the vasa recta [84], and endoscopic hemostasis is provided by epinephrine injection $[35,62,85,86]$, coagulation $[35,62,85$, 87], clipping [35, 58, 62, 67, 80, 85, 86, 88-93], and ligation (EBL and detachable snare ligation) [83, 88, 91, 9497]. The over-the-scope clip system was also used to achieve endoscopic hemostasis in a recent study [98].

In a prospective cohort study reporting the effectiveness of endoscopic coagulation and/or epinephrine injection for definitive colonic diverticular bleeding [62], monopolar coagulation therapy had a risk of perforation when performed in colonic diverticula that did not con- tain muscularis propria (i.e., false diverticula). Therefore, coagulation is not recommended especially for bleeding from the base of the diverticulum. Epinephrine injection is associated with a risk of rebleeding [85] because its effect on hemostasis is temporary. Therefore, epinephrine injection therapy should be used concurrently with other modalities [58, 62].

Because of its rare association with tissue damage, endoscopic clipping is used commonly for hemostasis in patients with colonic diverticular bleeding $\left[58,67,80,88_{-}\right.$ 93]. Clipping is largely classified into a direct method, in which vasa recta are clipped directly, and an indirect method, in which the openings of the diverticula are closed. The indirect method has a possibility of high recurrence because the vasa recta are not clipped and are not occluded. Therefore, the direct method should be used as far as possible [58, 80, 92]. However, because colonic diverticular bleeding often occurs at the base of diverticulum [84], there are not many opportunities for the direct method to achieve hemostasis [80]. When the direct method is difficult to perform, alternative modalities such as ligation should be selected.

The utility of endoscopic ligation such as EBL and detachable snare ligation has been shown in recent studies [83, 88, 91, 94-97]. Endoscopic ligation enables mechanical hemostasis regardless of whether bleeding is from the base or neck. However, in EBL, a colonoscope needs to be reinserted after attaching a ligation device at the tip.

No randomized controlled studies have compared the utility of different modalities to date. In a recent systematic review and meta-analysis of observational studies [14], despite no significant differences in the rates of initial hemostasis and early rebleeding ( $\leq 30$ day) between the coagulation group $(n=33)$, clipping group $(n=192)$, and ligation group $(n=156)$, the rate of transition to arterial embolization and surgery was lower in the ligation group $(0.00 ; 95 \%$ CI $0.00-0.01)$ than that in the coagulation group $(0.18 ; 95 \%$ CI $0.00-0.61)$ or the clipping group $(0.08$; $95 \%$ CI $0.03-0.16)$.

The unexpected complications of endoscopic clipping and EBL are septicemia and intestinal perforation respectively $[21,99]$. In colonic diverticular bleeding, endoscopic hemostasis needs to be performed carefully, regardless of the method used, because bleeding is from false diverticula that do not have muscularis propria. At present, the risk of intestinal perforation associated with endoscopic ligation cannot be fully evaluated due to insufficient data. However, because it is an unexpected adverse event that requires surgical intervention, it is important to consider the balance between the advantages and disadvantages of ligation. 
CQ16: How effective and safe is ligation as endoscopic hemostasis for colonic diverticular bleeding?

Statement: In colonic diverticular bleeding, the low incidence of early rebleeding after ligation suggests that ligation is relatively effective, but more evidence needs to be accumulated. Intestinal perforation and colonic diverticulitis have been reported as unexpected adverse events of ligation therapy, so it is necessary to pay attention to the balance between the advantages and disadvantages of this procedure.

Quality of evidence: C

Explanation

EBL and detachable snare ligation have been performed as endoscopic ligation methods for hemostasis of colonic diverticular bleeding.

In patients with colonic diverticular bleeding, the rate of initial hemostasis was $87-100 \%$, with occasional unsuccessful cases [83, 91, 94-97, 100]. Epinephrine injection therapy is selected when the small opening and large base of a diverticulum makes the aspiration and eversion of the diverticulum difficult $[94,96]$. In some patients, the diverticular opening is larger than the diameter of a standard band ligator, and therefore, EBL cannot be performed; however, this is rare. In such patients, direct clipping is performed if visible vessels are identified [94].

The rate of early rebleeding ( $\leq 30$ days) is $0-15 \%$ in ligation for colonic diverticular bleeding [83, 91, 94-97, 100]. In the case of early rebleeding, endoscopic hemostasis such as ligation and clipping is performed [94], but when effective endoscopic hemostasis cannot be achieved, arterial embolization may be a viable alternative.

A previous study has reported the occurrence of delayed perforation after EBL for diverticular bleeding in the sigmoid colon of patients with connective tissue disease on long-term steroid therapy [21], suggesting the association between delayed wound healing risk of perforation. There is also a report of post-EBL colonic diverticulitis [101].

Because the amount of data accumulated for ligation is limited, it is difficult to specify the frequency of occurrence of intestinal perforation and diverticulitis. Because intestinal perforation is an unexpected adverse event that requires surgical intervention, it is necessary to pay attention to the balance between advantages and disadvantages.

CQ17: What selection criteria are used for arterial embolization and colectomy, in patients with ongoing bleeding unresponsive to endoscopic examination or treatment?

Statement: It is recommended that minimally invasive arterial embolization be performed while managing hemodynamics. Colectomy is recommended only when arterial embolization is not indicated or was unsuccessful.

Quality of evidence: D

Strength of recommendation: Do it

Agreement rate: $100 \%$

Explanation

Arterial embolization and colectomy may be considered alternative hemostatic methods for patients who are bleeding continuously and are unresponsive to endoscopic examination and treatment $[34,102]$. Although no randomized controlled studies have compared arterial embolization and colectomy, minimally invasive arterial embolization is generally recommended for this group of patients. When performing arterial embolization, CT angiography is recommended for identifying the site of bleeding. Angiography is useful in detecting the site of bleeding in patients with systolic blood pressure $<90 \mathrm{~mm} \mathrm{Hg}$ and requiring transfusion of $\geq 5 \mathrm{U}$ of packed red blood cells in $24 \mathrm{~h}$ [103]; it also enables treatment without changing modalities. When extravasation is observed on CT or angiography, hemostasis may be achieved by arterial embolization. Bowel preparation, which is needed for colonoscopy, is not required for arterial embolization. Colectomy is associated with high mortality $[104,105]$, so it is recommended that other hemostatic methods be selected first.

CQ18: What are the indications for arterial embolization for colonic diverticular bleeding?

Statement: Arterial embolization is recommended for ongoing massive colonic diverticular bleeding that is difficult to achieve hemostasis by colonoscopy and as well as for continuous or recurrent colonic diverticular bleeding where it is difficult to identify the site of bleeding.

Quality of evidence: C

Strength of recommendation: Do it

Agreement rate: 100\%

Explanation

Endoscopic hemostasis is the first-line treatment for colonic diverticular bleeding. However, indications for arterial embolization are colonic diverticular bleeding that (i) is severe, (ii) is difficult to achieve hemostasis due to ongoing bleeding, (iii) is difficult to identify the site of bleeding, or (iv) recurs after endoscopic hemostasis [80, 106]. Also, because the success rate of endoscopic hemostasis is lower in patients with bleeding in the ascending colon compared with other sites (79.6 vs. $100 \%$ ), arterial embolization will be often required. Arterial embolization has a high likelihood of inducing intestinal ischemia in patients with no signs of extravasation; therefore, arterial embolization should not be performed in this group of patients [107].
12

Digestion 2019;99(suppl 1):1-26 DOI: $10.1159 / 000495282$
Nagata/Ishii/Manabe/Tomizawa/Urita/ Funabiki/Fujimori/Kaise 
CT angiography while stabilizing the hemodynamics is generally performed before arterial embolization, but it may be omitted when the site of bleeding has been already determined.

CQ19: Is arterial embolization effective for colonic diverticular bleeding?

Statement: Arterial embolization is highly effective when the site of bleeding is identified on angiography.

Quality of evidence: D

\section{Explanation}

When performing arterial embolization, it is absolutely necessary to identify the site of bleeding on angiography. It has been reported that the bleeding site is identified by angiography only in $24-48 \%$ of patients [108-110]. Different embolic materials such as metallic coils and nbutylcyanoacrylate are used in clinical practice, with no significant differences among them. The technical success rate is normally around $67-98 \%$ but was $100 \%$ when the number of patients was small $[80,108-114]$. The rebleeding rate is $12-50 \%$ [108-110], so patients need to be followed up carefully even when hemostasis is achieved.

CQ20: What are the complications of arterial embolization in patients with colonic diverticular bleeding?

Statement: The complications of arterial embolization is intestinal ischemia, resulting in perforation and stricture.

Quality of evidence: D

\section{Explanation}

Intestinal ischemia is a complication specific to arterial embolization for LGIB, occurring in $0-10 \%$ of the patients $[110,112,115,116]$. The incidence of intestinal ischemia increases when embolization is performed in multiple vasa recta. According to a previous study, the incidence of intestinal ischemia was 0 among 6 patients when embolization was performed in 1 vasa recta, but perforation or stricture was observed in both of 2 patients when embolization was performed in $\geq 3$ vasa recta [117]. Conservative treatment may be sufficient to improve intestinal ischemia, but perforation requires surgery. Other complications directly attributable to angiography include lower limb ischemia and infection [110]. It is also important to pay attention to contrast-induced nephropathy and other side effects associated with contrast media.

CQ21: What are the indications for hemostasis by emergency colectomy in colonic diverticular bleeding?

Statement: Emergency colectomy is recommended for severe colonic diverticular bleeding after unsuccessful endoscopic therapy or arterial embolization.
Quality of evidence: C

Strength of recommendation: Do it

Agreement rate: 100\%

Explanation

Due to recent technological advances in endoscopy and improved treatment outcomes in arterial embolization, colectomy is no longer the first-line treatment for colonic diverticular bleeding $[34,118,119]$. Therefore, indications for hemostasis by emergency colectomy include severe cases of colonic diverticular bleeding for which endoscopic therapy or arterial embolization is unsuccessful. Partial colectomy is performed when the bleeding site is known before surgery; otherwise, subtotal colectomy is performed. To avoid subtotal colectomy and maintain quality of life, it is recommended that the site of bleeding be identified and partial colectomy performed.

\section{CQ22: Is barium impaction therapy effective for co-} lonic diverticular bleeding?

Statement: Barium impaction therapy is not recommended because its effect on hemostasis is presently not supported by sufficient evidence and also because residual barium interferes with subsequent endoscopic therapy, arterial embolization, and colectomy. However, evidence suggests that barium impaction therapy prevents rebleeding after achieving hemostasis.

Quality of evidence: C

Strength of recommendation: Probably don't do it

Agreement rate: $100 \%$

Explanation

The effects of barium impaction therapy are mainly divided into hemostasis and prevention of recurrence after achieving hemostasis.

To evaluate the hemostatic effect of barium, a study performed barium therapy ( $400 \mathrm{~mL}$ of $200 \mathrm{w} / \mathrm{v} \%$ barium) in 4 patients with colonic diverticular bleeding of unknown origin and observed no cases of rebleeding over 1 year [120]. Hemostatic effect was also maintained over 1 year in 2 studies performing barium therapy $(200 \mathrm{w} / \mathrm{v} \%)$ for recurrent severe colonic diverticular bleeding [121, 122]. Endoscopy-guided barium impaction therapy has been developed to address negative factors associated with barium impaction therapy, such as need for X-ray fluoroscopy, technical disparity, and need for changing positions [19]. No rebleeding or complication was observed in 3 patients with colonic diverticular bleeding of unknown origin who had undergone single-balloon enteroscopy to spray a large amount $(1,500-2,000 \mathrm{~mL})$ of highly concentrated barium $(200 \mathrm{w} / \mathrm{v} \%)$ in the distal area of the colon [19]. However, because these hemostatic ef- 
fects were observed in case studies and retrospective studies with a small number of patients, available evidence is poor. It is important to keep in mind that barium therapy makes subsequent endoscopic therapy and arterial embolization difficult due to residual barium.

Other studies have reported the effect of barium therapy in preventing the recurrence of colonic diverticular bleeding after spontaneous hemostasis [123-125]. In a randomized controlled study conducted in Japan, it was found that the rate of rebleeding was significantly lower in the barium group than that in the conservative group [126]. However, another retrospective study from Japan indicated that the rate of rebleeding was high, at $54.5 \%$, at the median timepoint ( 7 months) when barium was used at a low concentration $(60 \mathrm{w} / \mathrm{v} \%)$. One study regarding the safety of barium impaction therapy $(150 \mathrm{w} / \mathrm{v} \%)$ in 20 patients revealed 1 case of perforation [125].

CQ23: Does the discontinuation of NSAIDs effectively prevent the recurrence of colonic diverticular bleeding?

Statement: The recurrence of colonic diverticular bleeding may be prevented by discontinuing NSAIDs. Therefore, the discontinuation of NSAIDs is proposed when feasible.

Quality of evidence: C

Strength of recommendation: Probably do it

Agreement rate: $100 \%$

\section{Explanation}

Because the use of non-aspirin NSAIDs is a risk factor for the occurrence and recurrence of colonic diverticular bleeding, the key point to long-term prevention of rebleeding is whether it is possible to discontinue medications that carry risk [34]. A prospective cohort study from Japan investigating the effect of drug discontinuation and continuation in 41 patients who were admitted for colonic diverticular bleeding and were taking NSAIDs reported that the rate of recurrence over 12 months after hospital discharge was $9.4 \%$ in the discontinuation group and $77 \%$ in the continuation group, indicating that drug discontinuation significantly suppressed recurrence $(p<0.01)$ [127]. Patients in the discontinuation group underwent alternative therapy for treatment of the primary disease and pain management [127]. In multivariate analysis, the hazard ratio associated with the discontinuation of NSAIDs was 0.06 (95\% CI 0.01-0.31), showing an extremely high suppressive effect [127]. However, the level of evidence is low due to the paucity of other studies reporting the effect of discontinuing NSAIDs at the time of hospital discharge. Nonetheless, compared with antithrombogenic drugs, the discontinua- tion of NSAIDs is thought to have a lower risk of thromboembolism and is therefore relatively safe. Before discontinuing NSAIDs, it is important to consider treatment of the primary disease, alternative drugs (pain medications other than NSAIDs), fomentation (anti-inflammatory analgesic plaster or patch), and nerve block. An earlier study has indicated that COX-2 selective inhibitors are associated with risk of LGIB [128], and therefore any change in the administration of these drugs would have a negative effect on preventing recurrence of LGIB. It is important to fully explain to patients who have difficulty in discontinuing the drugs that the risk of recurrence increases with repeat administration of NSAIDs.

CQ24: Should anticoagulant therapy be resumed after temporary discontinuation due to colonic diverticular bleeding, and if so, when?

Statement: It is recommended that anticoagulant therapy be resumed after hemostasis is confirmed.

Quality of evidence: C

Strength of recommendation: Do it

Agreement rate: $100 \%$

\section{Explanation}

No studies have investigated whether anticoagulant therapy should be resumed after temporary discontinuation in patients with colonic diverticular bleeding. However, a couple of cohort studies investigating the effect of readministering anticoagulants after temporary discontinuation due to acute GI bleeding $[48,50,129]$ have shown that continued discontinuation of anticoagulant therapy is associated with a risk of thromboembolism and subsequent mortality [48, 50, 129]. A meta-analysis has also shown that the risk of thromboembolism and subsequent mortality decreases by temporarily discontinuing and later resuming anticoagulant therapy [47]. Despite the potential risk, no significant increase in rebleeding was observed in the meta-analysis (hazard ratio: $1.20 ; p=0.10$ ) [47]. Based on these findings, it is recommended that anticoagulant therapy that has been discontinued temporarily be resumed. A study investigating the timing of readministration has shown that drug readministration $\leq 7$ days after discontinuation was associated with a lower risk of thromboembolism and subsequent mortality than readministration $\geq 30$ days after discontinuation [129]. Therefore, anticoagulant readministration is recommended after the hemostasis method is completed (e.g., endoscopic hemostasis and arterial embolization), when there is endoscopic confirmation of the absence of active bleeding in the colorectum, or when bleeding-related symptoms have disappeared (when endoscopy is difficult to perform).
Nagata/Ishii/Manabe/Tomizawa/Urita/ Funabiki/Fujimori/Kaise 
CQ25: Should antiplatelet therapy be resumed after temporary discontinuation due to colonic diverticular bleeding, and if so, when?

Statement: It is recommended that antiplatelet therapy be resumed after confirmation of hemostasis. Not resuming antiplatelet therapy for primary prevention is optional.

Quality of evidence: C

Strength of recommendation: Do it

Agreement rate: $100 \%$

Explanation

No studies have investigated whether antiplatelet therapy should be resumed after temporary discontinuation in patients with colonic diverticular bleeding. Retrospective cohort studies in patients with aspirinassociated acute lower GIB $[46,49,51]$ have shown that the discontinuation of aspirin was associated with a significantly lower rate of rebleeding but also a significantly higher number of adverse cardiovascular events compared with the continuation and re-administration of aspirin [46]. A randomized controlled study of patients with aspirin-associated upper GI bleeding has also demonstrated increased risks of cardiovascular events and mortality after discontinuation of aspirin, suggesting the advantages of resuming aspirin early [51]. Based on these findings, it is recommended that antiplatelet therapy be resumed after temporary discontinuation. There is currently insufficient data to decide on the timing for antiplatelet therapy resumption. Guidelines in the United States and Europe recommend resuming therapy in $5-7$ days $[34,54,130]$. Antiplatelet readministration is recommenced after the hemostasis method is successfully completed (e.g., endoscopic hemostasis or arterial embolization), there is endoscopic confirmation of the absence of active bleeding of the colorectum, or when bleeding-related symptoms have disappeared (when endoscopy is difficult to perform).

In prescribing low-dose aspirin for the primary prevention of arteriosclerotic diseases such as hypertension, dyslipidemia, and diabetes, the risk of bleeding outweighs the risk of thromboembolism [34]. Therefore, it is important not to resume administration (i.e., stop low-dose aspirin).

No study has investigated the readministration of antiplatelets other than aspirin (e.g., clopidogrel, ticlopidine, cilostazol, and dipyridamole). Therefore, it is unclear whether rebleeding is prevented by the readministration of these antiplatelets in patients for whom aspirin has been discontinued.

Diverticular Disease Guideline
CQ26: Does endoscopic hemostasis prevent the recurrence of colonic diverticular bleeding over a longterm follow-up period?

Statement: Endoscopic hemostasis is not expected to exert a long-term preventive effect on the recurrence of colonic diverticular bleeding.

Quality of evidence: D

Explanation

A control group is needed to verify the preventive effect of endoscopic therapy in patients with SRH of diverticula. In a cohort study evaluating colonic diverticular bleeding with a known culprit vessel, which is an indication for endoscopic therapy, Jensen et al. [62] performed conservative management and endoscopic therapy in 17 and 10 patients, respectively, and found no delayed rebleeding in either group. This suggests that endoscopic therapy is not superior in terms of long-term prevention. In other studies of patients who underwent endoscopic therapy for colonic diverticular bleeding, the rates of rebleeding varied between $0 \%$ and $23 \%$ after follow-up observation of $\geq 1$ month $[58,62,86,88,92,96,97]$, suggesting that the rate of rebleeding depends on the treatment method. A Japanese study comparing the hemostatic effects of endoscopic clipping and EBL revealed a lower rate of rebleeding with EBL than with clipping [88]. Specifically, the early rebleeding rate was $38 \%$ in the clipping group and significantly lower at $14 \%$ in the EBL group [88]. Also, in one study, disappearance and scarring of diverticula was observed in the colon of 11 of 24 patients (46\%) treated with EBL, 5 of whom (45\%) had delayed rebleeding, indicating that rebleeding can occur at a different diverticulum over the long term [88]. CQ26 has been assigned a level of evidence of D because previous studies investigating the preventive effect of endoscopic hemostasis on colonic diverticular bleeding have been single-center, retrospective, or small-scale studies associated with problems such as short follow-up period and insufficient collation of factors associated with rebleeding such as discontinuation of antithrombogenic drugs and NSAIDs. Although endoscopic therapy exerts a hemostatic effect on active bleeding, at present it cannot be expected to provide long-term preventive effects.

\section{Diagnosis and Treatment of Colonic Diverticulitis}

CQ27: Is it essential to examine complications such as abscess, perforation, and peritonitis at initial assessment for colonic diverticulitis?

Statement: It is recommended that complications such as abscess, perforation, and peritonitis be exam-

Digestion 2019;99(suppl 1):1-26

DOI: $10.1159 / 000495282$ 
ined for at the initial assessment for colonic diverticulitis.

Quality of evidence: C

Strength of recommendation: Do it

Agreement rate: $100 \%$

Explanation

Because abscess formation and perforation resulting from the progression of colonic diverticulitis may lead to peritonitis, sepsis, and shock, it is desirable to develop a treatment strategy based on proper assessment [131]. A large-scale study conducted in the United Kingdom has shown that the mortality of patients with complicated colonic diverticulitis, perforation, and abscess was 4.6 times higher than that of ordinary citizens [132]. In that study, the mortality of patients with fistula and stricture as complications was also shown to be 2.6 and 2.4 times higher, respectively, than that of ordinary citizens [132]. Furthermore, a multicenter cross-sectional study conducted in Japan has shown a long hospitalization rate and a high mortality rate among patients with complicated colonic diverticulitis with abscess, perforation, and fistula [133]. Based on these findings, it is recommended that abscess, perforation, and peritonitis be examined for in patients with colonic diverticulitis for the first time because these complications are associated with poor prognosis and intervention with colectomy will be required.

CQ28: Is an imaging test (CT or US) necessary for the diagnosis of colonic diverticulitis, in addition to physical examination and blood tests?

Statement: In addition to physical examination and blood tests, an imaging test (CT or US) is recommended for the diagnosis of colonic diverticulitis.

Quality of evidence: C

Strength of recommendation: Do it

Agreement rate: $88 \%$

Explanation

The common symptoms of colonic diverticulitis without abscess or perforation are abdominal pain, tenderness limited to the site of diverticula, fever, nausea, and vomiting. Due to similar symptomatology, physical examination and blood tests are not sufficient to differentiate right-sided diverticulitis, which is common in Japan, from acute appendicitis, so an imaging test (CT or US) should be performed for differential diagnosis [134]. In contrast, many patients with colonic diverticulitis accompanied by generalized peritonitis and abscess, which often requires intervention with colectomy, present with exacerbated abdominal symptoms, muscle guarding, formation of a mass, and inflammatory response such as leukocytosis, elevated Creactive protein level, and increased erythrocyte sedimentation rate. This suggests that physical examination findings and hematological findings are worse in patients with diverticulitis accompanied by abscess or perforation than in those not accompanied by abscess or perforation. However, research has shown that it is difficult to completely exclude complications with abscess or perforation based solely on physical examination findings and hematological findings, suggesting that an imaging test (CT or US) is required for definitive diagnosis $[135,136]$. Given the above, it is recommended that an imaging test (CT or US) be performed in addition to physical examination and blood tests for the diagnosis of colonic diverticulitis.

CQ29: What diagnostic imaging modality is useful for colonic diverticulitis?

Statement: CT is recommended as a diagnostic modality for colonic diverticulitis.

Quality of evidence: C

Strength of recommendation: Do it

Agreement rate: $88 \%$

Explanation

It is important to select a modality that produces objective and reproducible images with minimum oversight. In daily clinical practice in Japan, CT imaging has been frequently used as a diagnostic modality for colonic diverticulitis [136, 137]. Given that the classification system for staging colonic diverticulitis was established based on CT findings, it is reasonable to consider CT as the gold standard. However, due to recent technological advances in US, it is now useful for the diagnosis of colonic diverticulitis and assessment of treatment outcomes [138]; the diagnostic ability of US was even comparable to that of CT [139]. Therefore, depending on the facility, US may be the first modality of choice for colonic diverticulitis. However, it is important to keep in mind that US is still associated with disparity between facilities and problems with reproducibility.

CQ30: Should colonoscopy be performed to exclude colorectal cancer after remission of colonic diverticulitis?

Statement: Although the association between colonic diverticulitis and colorectal cancer is currently unknown, colonoscopy is recommended at least once to eliminate the possibility of lesions other than colonic diverticulosis as the possible cause of disease.

Quality of evidence: C

Strength of recommendation: Do it
16

Digestion 2019;99(suppl 1):1-26

DOI: $10.1159 / 000495282$
Nagata/Ishii/Manabe/Tomizawa/Urita/ Funabiki/Fujimori/Kaise 
Agreement rate: $100 \%$

\section{Explanation}

The association between colonic diverticulitis and colorectal cancer is currently unknown. However, because it is important to eliminate the involvement of lesions other than colonic diverticulosis as the possible cause of disease [140-143], colonoscopy is recommended at least once in patients who have never undergone the procedure.

CQ31: Are dietary restriction and bowel rest effective treatments for colonic diverticulitis without abscess or perforation?

Statement: Dietary restriction and bowel rest are recommended for colonic diverticulitis without abscess or perforation in patients admitted to the hospital with clinical features of inflammatory response and high fever.

Quality of evidence: D

Strength of recommendation: Probably do it

Agreement rate: 100\%

Explanation

Based on past experience, antibiotic therapy and follow-up management of abdominal pain are often performed for colonic diverticulitis without fever, peritoneal signs, or imaging findings of abscess or perforation in the outpatient clinic [144]. Considering that dietary intake increases intestinal internal pressure and induces intestinal peristalsis, dietary restriction and bowel rest are thought to be beneficial for treatment of colonic diverticulitis. However, dietary restriction and bowel rest are not necessarily performed in actual outpatient clinical practice. Even in the absence of abscess or perforation, patients with fever and hematological findings of severe inflammatory response are often hospitalized for antibiotic therapy, dietary restriction, and bowel rest [145]. Therefore, even though no studies have yet investigated the effect of bowel rest and dietary restriction on colonic diverticulitis, it is proposed that dietary restriction and bowel rest be included in the treatment strategy for colonic diverticulitis requiring inpatient care, even in the absence of abscess or perforation.

CQ32: Is antibiotic therapy effective for colonic diverticulitis without abscess or perforation?

Statement: Antibiotic therapy has been reported to be unnecessary for colonic diverticulitis without abscess or perforation, but no studies have been conducted in Japan. Therefore, the efficacy of antibiotic therapy among Japanese patients is currently unclear. Antibiotic therapy is considered acceptable in present clinical practice.

Diverticular Disease Guideline
Quality of evidence: C

Strength of recommendation: Probably do it

Agreement rate: 100\%

Explanation

Based on past experience, antibiotic therapy and follow-up management of abdominal pain are often performed for colonic diverticulitis without fever, peritoneal signs, or imaging findings of abscess or perforation in the outpatient clinic [146]. However, because the excessive use of antibiotics is a recent problem, it has been proposed that the use of antibiotics be limited to the minimum required and for the shortest duration necessary [147]. In recent randomized controlled studies of colonic diverticulitis without abscess or perforation, antibiotic therapy made no significant difference in the incidence of development of complications or rate of recurrence [148151]. However, these studies had problems such as incomplete randomization and exclusion of patients with certain risk factors such as high fever and poor general condition. Furthermore, because similar randomized controlled studies have not been conducted in Asian countries, it is currently unclear whether antibiotic therapy is necessary to treat colonic diverticulitis without abscess or perforation in Japanese patients. It is therefore concluded that antibiotic therapy is acceptable, but further study is needed to address this issue.

CQ33: Is antibiotic therapy recommended for colonic diverticulitis without abscess or perforation in pregnant or immunocompromised patients?

Statement: Antibiotic therapy is recommended for colonic diverticulitis without abscess or perforation in immunocompromised patients. As for patients who are pregnant, it is recommended that discussion be held with the obstetrician before a final decision on antibiotic therapy is made.

\section{Quality of evidence: B}

Strength of recommendation: Do it

Agreement rate: 100\%

\section{Explanation}

Immunocompromised patients reportedly have a high incidence of colonic diverticulitis [152-155] as well as complications such as abscess or perforation. Therefore, antibiotic therapy is recommended to prevent the exacerbation of colonic diverticulitis in immunocompromised patients without abscess or perforation [155]. As for pregnant patients with colonic diverticulitis without abscess or perforation, due to the potential effect of antibiotics on infants, it is recommended that the use of antibiotic therapy be discussed with the obstetrician [152-154].

Digestion 2019;99(suppl 1):1-26

DOI: $10.1159 / 000495282$ 
CQ34: Should colectomy be considered for recurrent colonic diverticulitis not accompanied by abscess or perforation?

Statement: Recurrent colonic diverticulitis without abscess or perforation alone is not always an indication for colectomy, but elective surgery may be considered in special cases, such as in immunocompromised patients.

Quality of evidence: C

Strength of recommendation: Probably do it

Agreement rate: $100 \%$

Explanation

In many patients, conservative treatment is sufficient to improve colonic diverticulitis without abscess or perforation. Accordingly, recurrent colonic diverticulitis without abscess or perforation alone is not an indication for surgery (and is not an indication for preventive colectomy). Elective surgery is considered based on the state of immunodeficiency (e.g., post-transplantation), severity of recurrent diverticulitis, presence of comorbidities, and age [156-158].

CQ35: Is emergency surgery necessary for colonic diverticulitis in patients presenting with generalized peritonitis?

Statement: Emergency surgery is recommended for colonic diverticulitis in patients presenting with generalized peritonitis.

Quality of evidence: A

Strength of recommendation: Do it

Agreement rate: $100 \%$

Explanation

Emergency surgery is a life-saving measure for colonic diverticulitis in patients with generalized peritonitis. In particular, emergency surgery is necessary for fecal peritonitis, in which colonic diverticulitis has entered the peritoneal cavity through free perforations. The operative mortality of patients with colonic diverticulitis and peritonitis is reportedly $6 \%$ for those with Hinchey III diverticulitis but increases to 35\% for those with Hinchey IV diverticulitis [159-161] (Fig. 4). Although Hartmann's operation is widely used, no standard surgical procedure has been established for complicated diverticulitis with generalized peritonitis because it is extremely difficult to perform a randomized controlled study of such patients. Therefore, a flexible approach is needed to select a surgical procedure tailored to the clinical situation (e.g., considering patient background and general health status).
CQ36: Are antibiotic therapy and bowel rest the first-line treatment modalities for complicated colonic diverticulitis with abscess and localized peritonitis?

Statement: Antibiotic therapy and bowel rest are proposed when the abscess measures $\leq 3 \mathrm{~cm}$. However, when the abscess is $\geq 5 \mathrm{~cm}$, it is proposed that US- or CT-guided drainage, antibiotic therapy, and bowel rest be instituted. For abscesses measuring 3-5 cm, treatment needs to be individualized based on disease state and feasibility of drainage depending on the availability of human and facility resources.

Quality of evidence: C

Strength of recommendation: Probably do it

Agreement rate: 100\%

Explanation

Previous studies have suggested that abscesses $\geq 5 \mathrm{~cm}$ are not effectively treated using antibiotic therapy alone $[162,163]$, and often the addition of drainage procedures is required. In contrast, small abscesses $\leq 3 \mathrm{~cm}$ are not an indication for drainage and are therefore treated with antibiotic therapy alone $[152,153]$. For abscesses measuring $3-5 \mathrm{~cm}$, individualized treatment methods need to be established based on disease state and the feasibility of drainage depending on the availability of staff and facility resources. Patients with no improvement after drainage need to be followed up carefully with colectomy in mind. In a study from the United States, abscess size as an indication for drainage was set at $4 \mathrm{~cm}$ [164], but because of the small number of patients and abscesses of varying size, this study is not used as evidence here.

CQ37: Is colectomy necessary for complicated colonic diverticulitis with abscess that is unresponsive to or exacerbated by antibiotic therapy?

Statement: Colectomy is recommended when antibiotic therapy and drainage are ineffective.

Quality of evidence: B

Strength of recommendation: Do it

Agreement rate: 100\%

Explanation

Percutaneous drainage for abscess is favored when conservative treatment with antibiotics is ineffective or even when complicated diverticulitis with abscess is exacerbated, whereas colectomy is recommended when drainage is ineffective or unsuccessful. Specifically, colectomy is indicated for patients with Hinchey III-IV diverticulitis, uncontrollable septicemia, and massive abscess untreatable with drainage, and those unresponsive to 3-day conservative treatment (e.g., antibiotic administration) [165]. Surgical procedures commonly selected are Hartmann's opera-
18

Digestion 2019;99(suppl 1):1-26 DOI: $10.1159 / 000495282$
Nagata/Ishii/Manabe/Tomizawa/Urita/ Funabiki/Fujimori/Kaise 
Fig. 4. Hinchey Classification. a Stage I; (b) Stage II; (c) Stage III; (d) Stage IV. Patients with stage I disease have small, confined pericolic or mesenteric abscesses, whereas those with stage II disease have larger abscesses, often confined to the pelvis. Stage III disease, or perforated diverticulitis, is present when a peridiverticular abscess has ruptured resulting in purulent peritonitis. Rupture of an uninflamed and unobstructed diverticulum into the free peritoneal cavity with fecal contamination, the socalled free rupture, signifies stage IV disease and carries the highest risk of an adverse outcome.

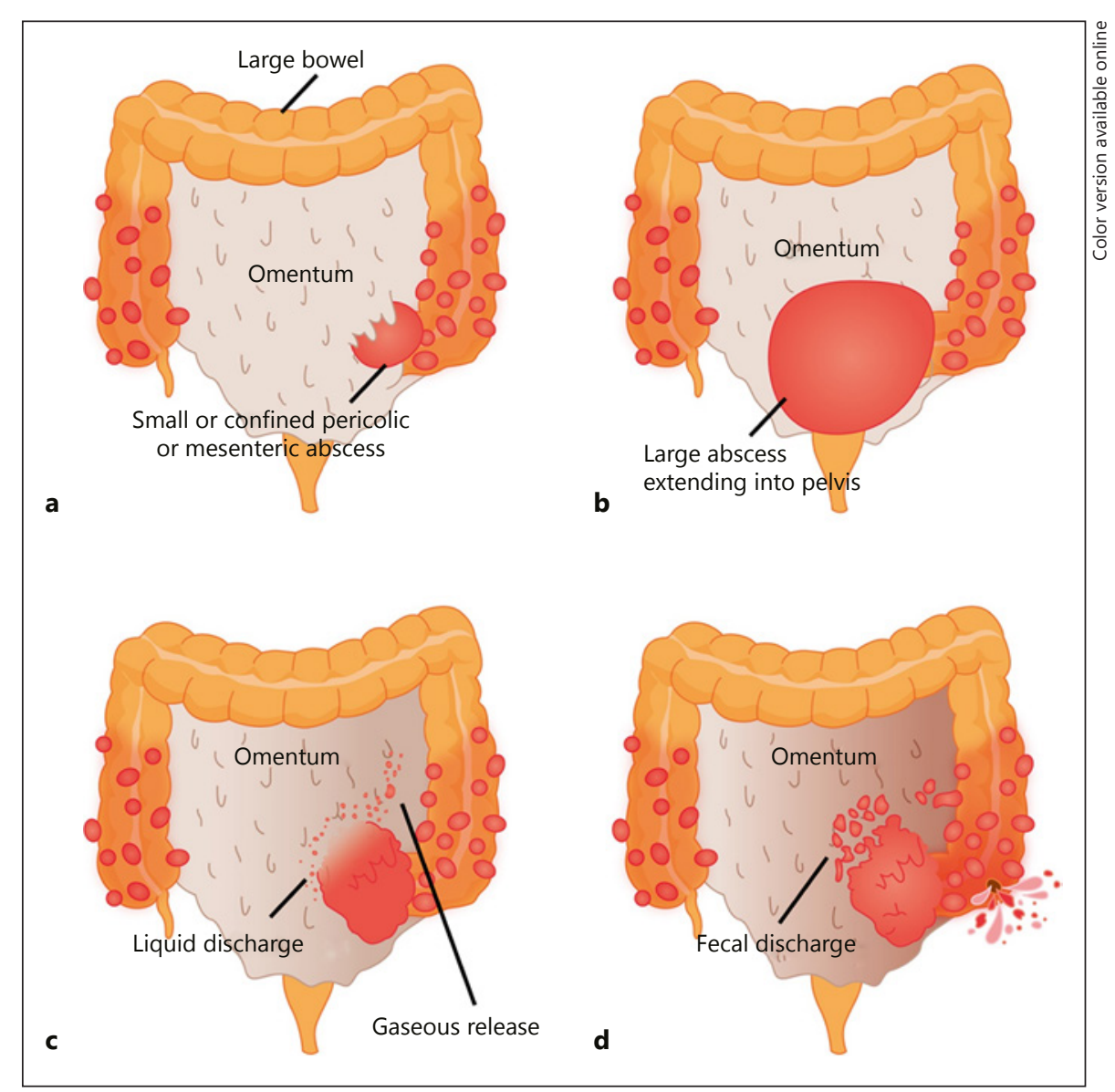

tion, colectomy, and drainage therapy [166]. In addition, the superiority of laparoscopic surgery over laparotomy in terms of severity of complications and length of hospital stay has been shown in recent years $[152,156,167]$.

CQ38: What is the definition of complicated colonic diverticulitis with fistula? Is colectomy necessary for treatment?

Statement: Complicated colonic diverticulitis with fistula is defined as the formation of fistulas between the colon and other organs due to diverticula, and colectomy is recommended for treatment of this condition.

Quality of evidence: B

Strength of recommendation: Do it

Agreement rate: $100 \%$

\section{Explanation}

A fistula is formed when an abscess caused by colonic diverticulitis ruptures into another organ or when adhesions are caused by inflammation associated with recurrent colonic diverticulitis. Fistulas occur in $4-20 \%$ of patients with colonic diverticulitis. Common sites of occur- rence are the bladder, sigmoid colon, uterus, vagina (after hysterectomy), kidneys, and skin [152, 168, 169]; with the bladder and sigmoid colon having the highest rates of occurrence. Colovesical fistula very rarely closes spontaneously because the pressure in the colon is much higher than that in the bladder. Colectomy is therefore the only treatment for colovesical fistula. Common clinical symptoms are pneumaturia, enteruria, and recurrent urinary tract infection. The incidence of colovesical fistula is higher in men than in women due to the presence of the uterus between the bladder and colon. Recent studies have reported the efficacy of one-stage resection in laparoscopic surgery occasionally [168-170], but the presence of inflammation makes the procedure more difficult than the standard surgery for colorectal cancer. Therefore, the surgery should be performed by skilled surgeons.

CQ39: What is the definition of complicated colonic diverticulitis with stricture? Is colectomy necessary for stricture with obstruction after remission of colonic diverticulitis? 
Statement: Complicated colonic diverticulitis with stricture is defined as the formation of strictures in the intestinal tract due to colonic diverticulitis, and colectomy is recommended for stricture that develops after remission of colonic diverticulitis.

Quality of evidence: B

Strength of recommendation: Do it

Agreement rate: $100 \%$

Explanation

Complicated colonic diverticulitis with stricture is defined as the formation of stricture in the colon due to diverticulitis. Stricture occurs more frequently in the colon (especially the sigmoid colon) on the left side compared with the right side, and it also occurs frequently with colovesical fistula [132, 152, 161, 171]. Spontaneous healing is difficult when stricture is present, and mortality increases 2.5 -fold in patients with complicated diverticulitis with stricture [132]. It is also important to differentiate from cancer. When cancer cannot be completely ruled out, surgical resection is recommended. Elective surgery scheduled for stricture with obstruction after the inflammation has resolved is beneficial because it not only decreases the risk of perforation and death, but also averts the need for permanent colostomy [171].

CQ40: What is the recurrence rate of colonic diverticulitis not accompanied by abscess or perforation?

Statement: The recurrence rate of colonic diverticulitis without abscess or perforation varies widely, from 13 to $47 \%$, depending on the definition of recurrence. Recurrent colonic diverticulitis is not necessarily a poor prognostic factor.

Quality of evidence: C

\section{Explanation}

When colonic diverticulitis was treated conservatively, the recurrence rate was $25 \%$ in a study conducted in 1969 [172]. However, in recent studies investigating the recurrence rate, the rate varied greatly depending on the definition of recurrence used. In left-sided colonic diverticulitis without abscess or perforation, the recurrence rate was $13 \%$ in patients who were diagnosed with colonic diverticulitis based on imaging findings [173] and $47 \%$ in patients diagnosed based on symptoms [174]. Furthermore, only $2-5 \%$ of patients with recurrent colonic diverticulitis had newly developed abscess or perforation and needed emergency surgery, indicating that the severity of recurrent colonic diverticulitis is relatively mild [175]. In a recent population-based study, the recurrence rate of colonic diverticulitis was $8 \%$ at 1 year, $17 \%$ at 5 years, and
$22 \%$ at 10 years. In addition, $12 \%$ of cases of recurrent colonic diverticulitis were accompanied by abscess or perforation, and the rate did not increase during the study period [132]. According to a recent meta-analysis, the recurrence rate of colonic diverticulitis is higher in patients with abscess as a complication and in young patients [176].

CQ41: What is the recurrence rate after conservative treatment of complicated colonic diverticulitis with abscess?

Statement: The rate of recurrence is thought to be 30 $47 \%$ after conservative treatment of complicated diverticulitis with abscess.

\section{Quality of evidence: B}

\section{Explanation}

In a study of complicated colonic diverticulitis with abscess, the rate of recurrence after 9.2 years (median value) of follow-up observation was approximately $30 \%$ in patients treated conservatively, which was significantly higher than the rate observed in the colectomy group [177]. In another study, the rate of recurrence after conservative treatment for diverticular abscess was $47 \%$ in patients with sigmoid diverticulitis, which often worsens [178]. Furthermore, in a recent meta-analysis, $38 \%$ of patients with complicated colonic diverticulitis had recurrence after conservative treatment, and abdominal symptoms persisted even after inflammation had improved [167]. Accordingly, the rates of recurrence vary depending on patient characteristics and time of study, but at present, the rate of recurrence after conservative treatment is $30-47 \%$ in patients with colonic diverticulitis complicated by abscess.

CQ42: Is conservative treatment recommended for recurrent colonic diverticulitis with a previous history of complication with abscess?

Statement: Conservative treatment is proposed when recurrent colonic diverticulitis is not accompanied by abscess. When abscess is present, however, the treatment should comply with CQ29-3.

Quality of evidence: B

Strength of recommendation: Probably do it

Agreement rate: $100 \%$

\section{Explanation}

Because it was previously thought that the rate of occurrence of abscess or perforation increases every time colonic diverticulitis recurs, colectomy was enthusiastically recommended especially in the United States and
Nagata/Ishii/Manabe/Tomizawa/Urita/ Funabiki/Fujimori/Kaise 
Europe $[167,177]$. However, a recent study has shown that in contrast to fistula, the incidence of abscess or perforation is higher in the first episode of colonic diverticulitis than in a repeat episode, suggesting that recurrent colonic diverticulitis is not a poor prognostic factor [178]. Another study has also reported that more often than not, recurrent colonic diverticulitis is not accompanied by abscess in patients who previously had complicated colonic diverticulitis with abscess [132]. Therefore, colectomy is not always necessary for recurrent colonic diverticulitis in a previous case of complicated colonic diverticulitis with abscess, and conservative treatment is proposed in the absence of abscess. If, however, abscess develops again, the treatment should comply with CQ37.

CQ43: Does any method effectively prevent the recurrence of colonic diverticulitis?

Statement: There is no method that effectively prevents the recurrence of colonic diverticulitis and has a high level of evidence.

\section{Quality of evidence: C}

\section{Explanation}

Due to technological advances in diagnostic imaging modalities and treatment techniques, many patients with colonic diverticulitis have been treated conservatively in recent years. Consequently, preventing the recurrence of colonic diverticulitis is currently an important challenge. This issue has been investigated mainly in the United States and Europe. First, a study investigating the effect of dietary therapy has reported that the recurrence rate of colonic diverticulitis decreases with an increasing amount of dietary fiber intake [179]. However, it is unclear whether recurrence or remission of colonic diverticulitis was confirmed from imaging findings or simply from abdominal symptoms in this study, and thus it is not plausible to conclude the beneficial effect of dietary fiber intake on the prevention of recurrent colonic diverticulitis. Second, a study investigating the effect of drug therapy has reported that mesalazine is effective in alleviating abdominal symptoms associated with colonic diverticulitis as well as preventing recurrence [180]. However, drug therapy with mesalazine is not actively recommended in Japan because the national health insurance system does not cover the procedure. In contrast, probiotics is thought to have no preventive effect against the recurrence of colonic diverticulitis, although they have been shown to suppress abdominal symptoms after remission [181, 182]. Also, a recent study has reported that the non- absorbable antibiotic rifaximin effectively prevented recurrence of colonic diverticulitis, but because the clinical characteristics of patients were often unclear, it cannot be said definitively that rifaximin prevents recurrence [183]. Taken together, despite the multiple studies that have investigated the prevention of colonic diverticulitis, the current results are not supported by high-quality evidence and therefore further investigation is required.

\section{Acknowledgments}

The authors thank the investigators and supporters for their participation. The authors also express special appreciation to Ms. Yoko Higuchi and Tomomi Sasaki.

\section{Ethics Statement}

The authors have no ethical conflicts to disclose.

\section{Disclosure Statement}

The authors have no conflicts of interest to declare. In accordance with the Guidelines Regarding Conflicts of Interest in Medical Research established by the Ethics Committee, the Japanese Gastroenterological Association obtained and scrutinized Declarations regarding financial relations with companies from the committee members of the Task Force for Guidelines for Colonic Diverticular Bleeding and Colonic Diverticulitis in Japan.

\section{Funding Sources}

This article was supported by a Grant-in-Aid from the Japanese Gastroenterological Association.

\section{Appendix}

Members of the Guidelines Committee who created and evaluated the "Guidelines for Colonic Diverticular Bleeding and Colonic Diverticulitis in Japan" are listed below. Committee chairperson: Mitsuru Kaise ${ }^{1}$

Development Committee members: Naoyoshi Nagata ${ }^{1}$, Naoki Ishii ${ }^{1}$, Noriaki Manabe ${ }^{1}$, Kenji Tomizawa ${ }^{1}$, Yoshihisa Urita ${ }^{2}$, Tomohiro Funabiki ${ }^{3}$, Shunji Fujimori ${ }^{2}$

Assessment Committee members: Tomohiro Kato ${ }^{1}$, Shinichi Nakamura $^{1}$

${ }^{1}$ Japanese Gastroenterological Association

2 Japanese Society of Gastroenterology

${ }^{3}$ Japanese Society of Interventional Radiology. 


\section{References}

1 Nagata N, Niikura R, Aoki T, Shimbo T, Itoh $\mathrm{T}$, Goda $\mathrm{Y}$, et al: Increase in colonic diverticulosis and diverticular hemorrhage in an aging society: lessons from a 9-year colonoscopic study of 28,192 patients in Japan. Int J Colorectal Dis 2014;29:379-385.

2 Yamamichi N, Shimamoto T, Takahashi Y, Sakaguchi Y, Kakimoto H, Matsuda R, et al: Trend and risk factors of diverticulosis in Japan: age, gender, and lifestyle/metabolic-related factors may cooperatively affect on the colorectal diverticula formation. PLoS One 2015; 104:e0123688.

3 Nagata N, Ishii N, Kaise M, Shimbo T, Sakurai $\mathrm{T}$, Akiyama J, et al: Long-term recurrent bleeding risk after endoscopic therapy for definitive colonic diverticular bleeding: band ligation versus clipping. Gastrointest Endosc 2018;88:841-853.e4.

4 Kinjo K, Matsui T, Hisabe T, Ishihara H, Kojima T, Chuman K, et al: Risk factors for severity of colonic diverticular hemorrhage. Intest Res 2018;163:458-466.

5 Umezawa S, Nagata N, Arimoto J, Uchiyama S, Higurashi T, Nakano K, et al: Contrast-enhanced CT for colonic diverticular bleeding before colonoscopy: a prospective multicenter study. Radiology 2018;2883:755-761.

6 Akutsu D, Narasaka T, Kobayashi K, Matsuda K, Wakayama M, Hiroshima Y, et al: Newly developed endoscopic detachable snare ligation therapy for colonic diverticular hemorrhage: a multicenter phase II trial (with videos). Gastrointest Endosc 2018;882:370-377.

7 Wada M, Kato M, Hirai Y, Kubosawa Y, Sunata $\mathrm{Y}, \mathrm{Abe} \mathrm{K}$, et al: Initial management of colonic diverticular bleeding: observational study. Digestion 2018;981:41-47.

8 Ichiba T, Hara M, Miyahara K, Urashima M, Shintani A, Naitou H, et al: Impact of computed tomography evaluation before colonoscopy for the management of colonic diverticular hemorrhage. J Clin Gastroenterol 2018, Epub ahead of print.

9 Kawanishi K, Kato J, Kakimoto T, Hara T, Yoshida T, Ida Y, et al: Risk of colonic diverticular rebleeding according to endoscopic appearance. Endosc Int Open 2018;61:E36-E42.

10 Higashi R, Kinugasa H, Nakagawa M: Endoscopic band ligation for colonic diverticular bleeding. Dig Endosc 2018;303:399.

11 Kishino T, Kitaichi T, Kanemasa K: Usefulness of water immersion observations to identify the stigmata of hemorrhage in colonic diverticular bleeding. Dig Endosc 2018;301:121-122.

12 Taki M, Oshima T, Tozawa K, Taniguchi Y, Tomita T, Ohda Y, et al: Analysis of risk factors for colonic diverticular bleeding and recurrence. Medicine (Baltimore) 2017;9638: e8090.

13 Uehara T, Matsumoto S, Miyatani H, Mashima H: Should emergency endoscopy be performed in all patients with suspected colonic diverticular hemorrhage? Clin Med Insights Gastroenterol 2017;10:1179552217728906.
14 Ishii N, Omata F, Nagata N, Kaise M: Effectiveness of endoscopic treatments for colonic diverticular bleeding. Gastrointest Endosc 2018;871:58-66.

15 Ito Y, Sakata Y, Yoshida H, Nonaka S, Fujii S, Tanaka Y, et al: High cost of hospitalization for colonic diverticular bleeding depended on repeated bleeding and blood transfusion: analysis with diagnosis procedure combination data in Japan. Digestion 2017;962:76-80.

16 Niikura R, Nagata N, Doyama H, Ota R, Ishii $\mathrm{N}$, Mabe K, et al: Current state of practice for colonic diverticular bleeding in 37 hospitals in Japan: a multicenter questionnaire study. World J Gastrointest Endosc 2016;820:785794.

17 Mizuki A, Tatemichi M, Nakazawa A, Tsukada N, Nagata H, Kanai T: Long-term clinical course after conservative and endoscopic treatment of colonic diverticular bleeding. Digestion 2016;944:186-191.

18 Kinjo K, Matsui T, Hisabe T, Ishihara H, Maki $\mathrm{S}$, Chuman $\mathrm{K}$, et al: Increase in colonic diverticular hemorrhage and confounding factors. World J Gastrointest Pharmacol Ther 2016; 73:440-446.

19 Koga M, Kusano C, Gotoda T, Suzuki S, Sato T, Fukuzawa M, et al: Barium impaction therapy with balloon occlusion for deep colonic diverticular bleeding: a three-case series. Endosc Int Open 2016;45:E560-E563.

20 Shimamura Y, Ishii N, Omata F, Imamura N, Okamoto T, Ego M, et al: Endoscopic band ligation for colonic diverticular bleeding: possibility of standardization. Endosc Int Open 2016;42:E233-E237.

21 Takahashi S, Inaba T, Tanaka N: Delayed perforation after endoscopic band ligation for treatment of colonic diverticular bleeding. Dig Endosc 2016;284:484.

22 Niikura R, Nagata N, Aoki T, Shimbo T, Tanaka S, Sekine K, et al: Predictors for Identification of stigmata of recent hemorrhage on colonic diverticula in lower gastrointestinal bleeding. J Clin Gastroenterol 2015;49:e24e30.

23 Yamada A, Niikura R, Yoshida S, Hirata Y, Koike K: Endoscopic management of colonic diverticular bleeding. Dig Endosc 2015;277: 720-725.

24 Yoshida M, Kinoshita Y, Watanabe M, Sugano K: JSGE Clinical Practice Guidelines 2014: standards, methods, and process of developing the guidelines. J Gastroenterol 2015;501: 4-10.

25 Peery AF, Barrett PR, Park D, Rogers AJ, Galanko JA, Martin CF, et al: A high-fiber diet does not protect against asymptomatic diverticulosis. Gastroenterology 2012;142:266272.

26 Peery AF, Keku TO, Martin CF, Eluri S, Runge T, Galanko JA, et al: Distribution and characteristics of colonic diverticula in a United States screening population. Clin Gastroenterol Hepatol 2016;14:980-985.
27 Nagata N, Niikura R, Shimbo T, Kishida Y, Sekine K, Tanaka S, et al: Alcohol and smoking affect risk of uncomplicated colonic diverticulosis in Japan. PLoS One 2013;812:e81137.

28 Niikura R, Nagata N, Shimbo T, Aoki T, Yamada A, Hirata Y, et al: Natural history of bleeding risk in colonic diverticulosis patients: a long-term colonoscopy-based cohort study. Aliment Pharmacol Ther 2015;419: 888-894.

29 Niikura R, Nagata N, Yamada A, Akiyama J, Shimbo T, Uemura N: Recurrence of colonic diverticular bleeding and associated risk factors. Colorectal Dis 2012;143:302-305.

30 Okamoto T, Watabe H, Yamada A, Hirata Y, Yoshida H, Koike K: The association between arteriosclerosis related diseases and diverticular bleeding. Int J Colorectal Dis 2012;279: 1161-1166.

31 Nishikawa H, Maruo T, Tsumura T, Sekikawa A, Kanesaka T, Osaki Y: Risk factors associated with recurrent hemorrhage after the initial improvement of colonic diverticular bleeding. Acta Gastroenterol Belg 2013;761: 20-24.

32 Aytac E, Stocchi L, Gorgun E, Ozuner G: Risk of recurrence and long-term outcomes after colonic diverticular bleeding. Int J Colorectal Dis 2014;293:373-378.

33 Poncet G, Heluwaert F, Voirin D, Bonaz B, Faucheron JL: Natural history of acute colonic diverticular bleeding: a prospective study in 133 consecutive patients. Aliment Pharmacol Ther 2010;323:466-471.

34 Strate LL, Gralnek IM: ACG Clinical Guideline: management of patients with acute lower gastrointestinal bleeding. Am J Gastroenterol 2016;1114:459-474.

35 Green BT, Rockey DC, Portwood G, Tarnasky PR, Guarisco S, Branch MS, et al: Urgent colonoscopy for evaluation and management of acute lower gastrointestinal hemorrhage: a randomized controlled trial. Am J Gastroenterol 2005;10011:2395-2402.

36 Laine L, Shah A: Randomized trial of urgent vs. elective colonoscopy in patients hospitalized with lower GI bleeding. Am J Gastroenterol 2010;105:2636-2641.

37 Srygley FD, Gerardo CJ, Tran T, Fisher DA: Does this patient have a severe upper gastrointestinal bleed? JAMA 2012;30710:1072-1079.

38 Strate LL, Orav EJ, Syngal S: Early predictors of severity in acute lower intestinal tract bleeding. Arch Intern Med 2003;1637:838843.

39 Velayos FS, Williamson A, Sousa KH, Lung E, Bostrom A, Weber EJ, et al: Early predictors of severe lower gastrointestinal bleeding and adverse outcomes: a prospective study. Clin Gastroenterol Hepatol 2004;26:485-490.

40 Strate LL, Saltzman JR, Ookubo R, Mutinga ML, Syngal S: Validation of a clinical prediction rule for severe acute lower intestinal bleeding. Am J Gastroenterol 2005; 1008: 1821-1827. 
41 Newman J, Fitzgerald JE, Gupta S, von Roon AC, Sigurdsson HH, Allen-Mersh TG: Outcome predictors in acute surgical admissions for lower gastrointestinal bleeding. Colorectal Dis 2012;148:1020-1026.

42 Chong V, Hill AG, MacCormick AD: Accurate triage of lower gastrointestinal bleed (LGIB) - a cohort study. Int J Surg 2016;25: 19-23.

43 Aoki T, Nagata N, Shimbo T, Niikura R, Sakurai T, Moriyasu S, et al: Development and validation of a risk scoring system for severe acute lower gastrointestinal bleeding. Clin Gastroenterol Hepatol 2016;14:1562-1570.

44 Kollef $\mathrm{MH}$, O’Brien JD, Zuckerman GR, Shannon W: BLEED: a classification tool to predict outcomes in patients with acute upper and lower gastrointestinal hemorrhage. Crit Care Med 1997;257:1125-1132.

45 Das A, Ben-Menachem T, Cooper GS, Chak A, Sivak MV Jr, Gonet JA, et al: Prediction of outcome in acute lower-gastrointestinal haemorrhage based on an artificial neural network: internal and external validation of a predictive model. Lancet 2003;3629392: 1261-1266.

46 Chan FK, Leung Ki EL, Wong GL, Ching JY, Tse YK, Au KW, et al: Risks of bleeding recurrence and cardiovascular events with continued aspirin use after lower gastrointestinal hemorrhage. Gastroenterology 2016;1512: 271-277.

47 Chai-Adisaksopha C, Hillis C, Monreal M, Witt DM, Crowther M: Thromboembolic events, recurrent bleeding and mortality after resuming anticoagulant following gastrointestinal bleeding. A meta-analysis. Thromb Haemost 2015;1144:819-825.

48 Sengupta N, Feuerstein JD, Patwardhan VR, Tapper EB, Ketwaroo GA, Thaker AM, et al: The risks of thromboembolism vs. recurrent gastrointestinal bleeding after interruption of systemic anticoagulation in hospitalized inpatients with gastrointestinal bleeding: a prospective study. Am J Gastroenterol 2015; 1102:328-335.

49 Derogar M, Sandblom G, Lundell L, Orsini N Bottai M, Lu Y, et al: Discontinuation of lowdose aspirin therapy after peptic ulcer bleeding increases risk of death and acute cardiovascular events. Clin Gastroenterol Hepatol 2013;111:38-42.

50 Witt DM, Delate T, Garcia DA, Clark NP, Hylek EM, Ageno W, et al: Risk of thromboembolism, recurrent hemorrhage, and death after warfarin therapy interruption for gastrointestinal tract bleeding. Arch Intern Med 2012;17219:1484-1491

51 Sung JJ, Lau JY, Ching JY, Wu JC, Lee YT, Chiu PW, et al: Continuation of low-dose aspirin therapy in peptic ulcer bleeding: a randomized trial. Ann Intern Med 2010;1521:19.

52 ASGE Standards of Practice Committee; Acosta RD, Abraham NS, Chandrasekhara V, Chathadi KV, Early DS, et al: The management of antithrombotic agents for patients undergoing GI endoscopy. Gastrointest Endosc 2016;831:3-16.

53 ASGE Standards of Practice Committee, Anderson MA, Ben-Menachem T, Gan SI, Appalaneni V, Banerjee S, et al: Management of antithrombotic agents for endoscopic procedures. Gastrointest Endosc 2009;706:10601070.

54 Barkun AN, Bardou M, Kuipers EJ, Sung J, Hunt RH, Martel M, et al: International consensus recommendations on the management of patients with nonvariceal upper gastrointestinal bleeding. Ann Intern Med 2010; 1522:101-113.

55 Veitch AM, Baglin TP, Gershlick AH, Harnden SM, Tighe R, Cairns S, et al: Guidelines for the management of anticoagulant and antiplatelet therapy in patients undergoing endoscopic procedures. Gut 2008;579:13221329.

56 Holbrook A, Schulman S, Witt DM, Vandvik PO, Fish J, Kovacs MJ, et al: Evidence-based management of anticoagulant therapy: antithrombotic therapy and prevention of thrombosis, 9th ed: American College of Chest Physicians Evidence-Based Clinical Practice Guidelines. Chest 2012;1412 Suppl:e152Se184S.

57 Ansell J, Hirsh J, Hylek E, Jacobson A, Crowther M, Palareti G: Pharmacology and management of the vitamin $\mathrm{K}$ antagonists: American College of Chest Physicians Evidence-Based Clinical Practice Guidelines (8th Edition). Chest 2008;133(6 suppl):160S198S.

58 Kaltenbach T, Watson R, Shah J, Friedland S, Sato T, Shergill A, et al: Colonoscopy with clipping is useful in the diagnosis and treatment of diverticular bleeding. Clin Gastroenterol Hepatol 2012;102:131-137.

59 Frattaroli FM, Casciani E, Spoletini D, Polettini E, Nunziale A, Bertini L, et al: Prospective study comparing multi-detector row CT and endoscopy in acute gastrointestinal bleeding. World J Surg 2009;3310:2209_ 2217.

60 Strate LL, Syngal S: Predictors of utilization of early colonoscopy vs. radiography for severe lower intestinal bleeding. Gastrointest Endosc 2005;611:46-52.

61 Al Qahtani AR, Satin R, Stern J, Gordon PH: Investigative modalities for massive lower gastrointestinal bleeding. World J Surg 2002; 265:620-625.

62 Jensen DM, Machicado GA, Jutabha R, Kovacs TO: Urgent colonoscopy for the diagnosis and treatment of severe diverticular hemorrhage. N Engl J Med 2000;3422:78-82.

63 Chaudhry V, Hyser MJ, Gracias VH, Gau FC: Colonoscopy: the initial test for acute lower gastrointestinal bleeding. Am Surg 1998;648: 723-728.

64 Richter JM, Christensen MR, Kaplan LM, Nishioka NS: Effectiveness of current technology in the diagnosis and management of lower gastrointestinal hemorrhage. Gastrointest Endosc 1995;412:93-98.
65 Garcia-Blazquez V, Vicente-Bartulos A, Olavarria-Delgado $A$, Plana $M N$, van der Winden D, Zamora J, et al: Accuracy of CT angiography in the diagnosis of acute gastrointestinal bleeding: systematic review and meta-analysis. Eur Radiol 2013;235:1181-1190.

66 Yamaguchi T, Manabe N, Hata J, Tanaka S, Haruma K, Chayama K: The usefulness of transabdominal ultrasound for the diagnosis of lower gastrointestinal bleeding. Aliment Pharmacol Ther 2006;238:1267-1272.

67 Sugiyama T, Hirata Y, Kojima Y, Kanno T, Kimura M, Okuda Y, et al: Efficacy of contrast-enhanced computed tomography for the treatment strategy of colonic diverticular bleeding. Intern Med 2015;5423:2961-2967.

68 Nagata N, Niikura R, Aoki T, Moriyasu S, Sakurai T, Shimbo T, et al: Role of urgent contrast-enhanced multidetector computed tomography for acute lower gastrointestinal bleeding in patients undergoing early colonoscopy. J Gastroenterol 2015;50:1162-1172.

69 Nakatsu S, Yasuda H, Maehata T, Nomoto M, Ohinata N, Hosoya K, et al: Urgent computed tomography for determining the optimal timing of colonoscopy in patients with acute lower gastrointestinal bleeding. Intern Med 2015; 546:553-558.

70 Obana T, Fujita N, Sugita R, Hirasawa D, Sugawara T, Harada Y, et al: Prospective evaluation of contrast-enhanced computed tomography for the detection of colonic diverticular bleeding. Dig Dis Sci 2013;587:1985-1990.

71 Sengupta N, Tapper EB, Feuerstein JD: Early versus delayed colonoscopy in hospitalized patients with lower gastrointestinal bleeding: a meta-analysis. J Clin Gastroenterol 2017; 514:352-359.

72 Seth A, Khan MA, Nollan R, Gupta D, Kamal $S$, Singh U, et al: Does urgent colonoscopy improve outcomes in the management of lower gastrointestinal bleeding? Am J Med Sci 2017; 3533:298-306.

73 Kouanda AM, Somsouk M, Sewell JL, Day LW: Urgent colonoscopy in patients with lower GI bleeding: a systematic review and meta-analysis. Gastrointest Endosc 2017;86: 107-117.

74 Nagata N, Niikura R, Sakurai T, Shimbo T, Aoki T, Moriyasu S, et al: Safety and effectiveness of early colonoscopy in management of acute lower gastrointestinal bleeding on the basis of propensity score matching analysis. Clin Gastroenterol Hepatol 2016;144:558564

75 Niikura R, Nagata N, Shimbo T, Sakurai T, Aoki T, Moriyasu S, et al: Adverse events during bowel preparation and colonoscopy in patients with acute lower gastrointestinal bleeding compared with elective non-gastrointestinal bleeding. PLoS One 2015;109:e0138000.

76 Lim DS, Kim HG, Jeon SR, Shim KY, Lee TH, Kim JO, et al: Comparison of clinical effectiveness of the emergent colonoscopy in patients with hematochezia according to the type of bowel preparation. J Gastroenterol Hepatol 2013;2811:1733-1737. 
77 Repaka A, Atkinson MR, Faulx AL, Isenberg GA, Cooper GS, Chak A, et al: Immediate unprepared hydroflush colonoscopy for severe lower GI bleeding: a feasibility study. Gastrointest Endosc 2012;762:367-373.

78 Saito K, Inamori M, Sekino Y, Akimoto K, Suzuki K, Tomimoto A, et al: Management of acute lower intestinal bleeding: what bowel preparation should be required for urgent colonoscopy? Hepatogastroenterology 2009; 56:1331-1334.

79 Ohyama T, Sakurai Y, Ito M, Daito K, Sezai S, Sato Y: Analysis of urgent colonoscopy for lower gastrointestinal tract bleeding. Digestion 2000;613:189-192.

80 Ishii N, Hirata N, Omata F, Itoh T, Uemura $M$, Matsuda M, et al: Location in the ascending colon is a predictor of refractory colonic diverticular hemorrhage after endoscopic clipping. Gastrointest Endosc 2012;766: $1175-1181$

81 Ikeya T, Ishii N, Shimamura Y, Nakano K, Ego M, Nakamura K, et al:Endoscopic band ligation for bleeding lesions in the small bowel. World J Gastrointest Endosc 2014;610:488-492.

82 Jensen DM, Ohning GV, Kovacs TO, Jutabha R, Ghassemi K, Dulai GS, et al: Natural history of definitive diverticular hemorrhage based on stigmata of recent hemorrhage and colonoscopic doppler blood flow monitoring for risk stratification and definitive hemostasis. Gastrointest Endosc 2016;832:416-423.

83 Shibata S, Shigeno T, Fujimori K, Kanai K, Yoshizawa K: Colonic diverticular hemorrhage: the hood method for detecting responsible diverticula and endoscopic band ligation for hemostasis. Endoscopy 2014;461:66-69.

84 Meyers MA, Alonso DR, Gray GF, Baer JW: Pathogenesis of bleeding colonic diverticulosis. Gastroenterology 1976;714:577-583.

85 Bloomfeld RS, Rockey DC, Shetzline MA: Endoscopic therapy of acute diverticular hemorrhage. Am J Gastroenterol 2001;968:23672372.

86 Ramirez FC, Johnson DA, Zierer ST, Walker GJ, Sanowski RA: Successful endoscopic hemostasis of bleeding colonic diverticula with epinephrine injection. Gastrointest Endosc 1996;43(2 Pt 1):167-170.

87 Foutch PG, Zimmerman K: Diverticular bleeding and the pigmented protuberance (sentinel clot): clinical implications, histopathological correlation, and results of endoscopic intervention. Am J Gastroenterol 1996; 9112:2589-2593.

88 Nakano K, Ishii N, Ikeya T, Ego M, Shimamura $\mathrm{Y}$, Takagi K, et al: Comparison of longterm outcomes between endoscopic band ligation and endoscopic clipping for colonic diverticular hemorrhage. Endosc Int Open 2015;35:E529-E533.

89 Couto-Worner I, Gonzalez-Conde B, Estevez-Prieto E, Alonso-Aguirre P: Colonic diverticular bleeding: urgent colonoscopy without purging and endoscopic treatment with epinephrine and hemoclips. Rev Esp Enferm Dig 2013;1058:495-498.
90 Fujino Y, Inoue Y, Onodera M, Kikuchi S, Endo S, Shozushima T, et al: Risk factors for early re-bleeding and associated hospitalization in patients with colonic diverticular bleeding. Colorectal Dis 2013;15:982-986.

91 Setoyama T, Ishii N, Fujita Y: Endoscopic band ligation (EBL) is superior to endoscopic clipping for the treatment of colonic diverticular hemorrhage. Surg Endosc 2011; 2511:3574-3578

92 Yen EF, Ladabaum U, Muthusamy VR, Cello JP, McQuaid KR, Shah JN: Colonoscopic treatment of acute diverticular hemorrhage using endoclips. Dig Dis Sci 2008;539:2480 2485.

93 Kumar A, Artifon E, Chu A, Halwan B: Effectiveness of endoclips for the treatment of stigmata of recent hemorrhage in the colon of patients with acute lower gastrointestinal tract bleeding. Dig Dis Sci 2011;5610:29782986.

94 Ikeya T, Ishii N, Nakano K, Omata F, Shimamura Y, Ego M, et al: Risk factors for early rebleeding after endoscopic band ligation for colonic diverticular hemorrhage. Endosc Int Open 2015;35:E523E528.

95 Akutsu D, Narasaka T, Wakayama M, Terasaki M, Kaneko T, Matsui H, et al: Endoscopic detachable snare ligation: a new treatment method for colonic diverticular hemorrhage. Endoscopy 2015;4711:10391042.

96 Ishii N, Setoyama T, Deshpande GA, Omata F, Matsuda M, Suzuki S, et al: Endoscopic band ligation for colonic diverticular hemorrhage. Gastrointest Endosc 2012;752: 382-387.

97 Farrell JJ, Graeme-Cook F, Kelsey PB: Treatment of bleeding colonic diverticula by endoscopic band ligation: an in-vivo and ex-vivo pilot study. Endoscopy 2003;3510: 823-829.

98 Wedi E, von Renteln D, Jung C, Tchoumak I, Roth V, Gonzales S, et al: Treatment of acute colonic diverticular bleeding in high risk patients, using an over-the-scope clip: a case series. Endoscopy 2016;48(S 01):E383E385.

99 Kume K, Yamasaki M, Yoshikawa I: Sepsis caused by endoscopic clipping for colonic diverticular bleeding: a rare complication. World J Gastroenterol 2009;1530:38173818.

100 Witte JT: Band ligation for colonic bleeding: modification of multiband ligating devices for use with a colonoscope. Gastrointest Endosc 2000;526:762-765.

101 Ishii N, Fujita Y: Colonic diverticulitis after endoscopic band ligation performed for colonic diverticular hemorrhage. ACG Case Rep J 2015;24:218-220.

102 Strate LL, Naumann CR: The role of colonoscopy and radiological procedures in the management of acute lower intestinal bleeding. Clin Gastroenterol Hepatol 2010;8: 333-343.
103 Abbas SM, Bissett IP, Holden A, Woodfield JC, Parry BR, Duncan D: Clinical variables associated with positive angiographic localization of lower gastrointestinal bleeding. ANZ J Surg 2005;7511:953957.

104 Plummer JM, Gibson TN, Mitchell DI, Herbert J, Henry T: Emergency subtotal colectomy for lower gastrointestinal haemorrhage: over-utilised or under-estimated? Int J Clin Pract 2009;636:865-868.

105 Chen CY, Wu CC, Jao SW, Pai L, Hsiao CW Colonic diverticular bleeding with comorbid diseases may need elective colectomy. J Gastrointest Surg 2009;133:516-520.

106 Zuccaro G Jr: Management of the adult patient with acute lower gastrointestinal bleeding. American College of Gastroenterology. Practice Parameters Committee. Am J Gastroenterol 1998;938:1202-1208.

107 Burgess AN, Evans PM: Lower gastrointestinal haemorrhage and superselective angiographic embolization. ANZ J Surg 2004; 748:635-638.

108 Yi WS, Garg G, Sava JA: Localization and definitive control of lower gastrointestinal bleeding with angiography and embolization. Am Surg 2013;794:375-380.

109 Gillespie CJ, Sutherland AD, Mossop PJ Woods RJ, Keck JO, Heriot AG: Mesenteric embolization for lower gastrointestinal bleeding. Dis Colon Rectum 2010;539: 1258-1264.

110 Maleux G, Roeflaer F, Heye S, Vandersmissen J, Vliegen AS, Demedts I, et al: Longterm outcome of transcatheter embolotherapy for acute lower gastrointestinal hemorrhage. Am J Gastroenterol 2009; 1048: 2042-2046.

111 Ahmed O, Jilani D, Sheth S, Giger M, Funaki B: Long-term results of microcoil embolization for colonic haemorrhage: how common is rebleeding? Br J Radiol 2015; 881051:20150203.

112 Adusumilli S, Gosselink MP, Ctercteko G, Pathmanathan N, El-Khoury T, Dutton P, et al: The efficacy of selective arterial embolization in the management of colonic bleeding. Tech Coloproctol 2014;186:529533.

113 Huang CC, Lee CW, Hsiao JK, Leung PC, Liu KL, Tsang YM, et al: N-butyl cyanoacrylate embolization as the primary treatment of acute hemodynamically unstable lower gastrointestinal hemorrhage. J Vasc Interv Radiol 2011;2211:1594-1599.

114 Tan KK, Nallathamby V, Wong D, Sim R: Can superselective embolization be definitive for colonic diverticular hemorrhage? An institution's experience over 9 years. J Gastrointest Surg 2010;141:112-118.

115 Hur S, Jae HJ, Lee M, Kim HC, Chung JW Safety and efficacy of transcatheter arterial embolization for lower gastrointestinal bleeding: a single-center experience with 112 patients. J Vasc Interv Radiol 2014;251: 10-19. 
116 Lipof T, Sardella WV, Bartus CM, Johnson $\mathrm{KH}$, Vignati PV, Cohen JL: The efficacy and durability of super-selective embolization in the treatment of lower gastrointestinal bleeding. Dis Colon Rectum 2008;513:301305.

117 Kodani M, Yata S, Ohuchi Y, Ihaya T, Kaminou T, Ogawa T: Safety and risk of superselective transcatheter arterial embolization for acute lower gastrointestinal hemorrhage with n-butyl cyanoacrylate: angiographic and colonoscopic evaluation. J Vasc Interv Radiol 2016;276:824-830.

118 Cirocchi R, Grassi V, Cavaliere D, Renzi C, Tabola R, Poli G, et al: New trends in acute management of colonic diverticular bleeding: a systematic review. Medicine (Baltimore) 2015;9444:e1710.

119 Farner R, Lichliter W, Kuhn J, Fisher T: Total colectomy versus limited colonic resection for acute lower gastrointestinal bleeding. Am J Surg 1999;1786:587-591.

120 Iwamoto J, Mizokami Y, Shimokobe K, Matsuoka T, Matsuzaki Y: Therapeutic barium enema for bleeding colonic diverticula: four case series and review of the literature. World J Gastroenterol 2008;1441:64136417.

121 Niikura R, Nagata N, Yamano K, Shimbo T Uemura N: High-dose barium impaction therapy is useful for the initial hemostasis and for preventing the recurrence of colonic diverticular bleeding unresponsive to endoscopic clipping. Case Rep Gastrointest Med 2013;2013:365954.

122 Matsuhashi N, Akahane M, Nakajima A: Barium impaction therapy for refractory colonic diverticular bleeding. AJR Am J Roentgenol 2003;1802:490-492.

123 Koperna T, Kisser M, Reiner G, Schulz F: Diagnosis and treatment of bleeding colonic diverticula. Hepatogastroenterology 2001;4839:702-705.

124 Nagata N, Niikura R, Shimbo T, Ishizuka N, Yamano K, Mizuguchi K, et al: High-dose barium impaction therapy for the recurrence of colonic diverticular bleeding: a randomized controlled trial. Ann Surg 2015; 2612:269-275.

125 Matsuura $M$, Inamori $M$, Nakajima $A$ Komiya Y, Inoh Y, Kawasima K, et al: Effectiveness of therapeutic barium enema for diverticular hemorrhage. World J Gastroenterol 2015;2118:5555-5559.

126 Fujimoto A, Sato S, Kurakata H, Nakano S, Igarashi Y: Effectiveness of high-dose barium enema filling for colonic diverticular bleeding. Colorectal Dis 2011;138:896-898.

127 Nagata N, Niikura R, Aoki T, Shimbo T, Sekine $\mathrm{K}$, Okubo $\mathrm{H}$, et al: Impact of discontinuing non-steroidal antiinflammatory drugs on long-term recurrence in colonic diverticular bleeding. World J Gastroenterol 2015;214:1292-1298.

128 Nagata N, Niikura R, Aoki T, Shimbo T, Kishida Y, Sekine K, et al: Lower GI bleeding risk of nonsteroidal anti-inflammatory drugs and antiplatelet drug use alone and the effect of combined therapy. Gastrointest Endosc 2014;80:1124-1131.

129 Qureshi W, Mittal C, Patsias I, Garikapati K, Kuchipudi A, Cheema G, et al: Restarting anticoagulation and outcomes after major gastrointestinal bleeding in atrial fibrillation. Am J Cardiol 2014;1134:662-668.

130 Sung JJ, Chan FK, Chen M, Ching JY, Ho KY, Kachintorn U, et al: Asia-Pacific Working Group consensus on non-variceal upper gastrointestinal bleeding. Gut 2011;609: 1170-1177.

131 Gala T, Alvi AR, Sheikh GM, Habib HY, Ghafoor Z, Mir TA, et al: Experience of managing complicated diverticulitis of colon: a retrospective case series from South Asian country. J Pak Med Assoc 2014;644: 409-414.

132 Humes DJ, West J: Role of acute diverticulitis in the development of complicated colonic diverticular disease and 1-year mortality after diagnosis in the UK: populationbased cohort study. Gut 2012;611:95-100.

133 Manabe N, Haruma K, Nakajima A, Yamada M, Maruyama Y, Gushimiyagi M, et al: Characteristics of colonic diverticulitis and factors associated with complications: a Japanese multicenter, retrospective, cross-sectional study. Dis Colon Rectum 2015;5812: 1174-1181.

134 Gilmore T, Jordan C, Edelstein E: Right-sided diverticulitis mimics appendicitis. J Emerg Med 2013;441:e29-e32.

135 van de Wall BJ, Draaisma WA, van der Kaaij RT, Consten EC, Wiezer MJ, Broeders IA: The value of inflammation markers and body temperature in acute diverticulitis. Colorectal Dis 2013;155:621-626.

136 Kaiser AM, Jiang JK, Lake JP, Ault G, Artinyan A, Gonzalez-Ruiz C, et al: The management of complicated diverticulitis and the role of computed tomography. Am J Gastroenterol 2005;1004:910-917.

137 Janes SE, Meagher A, Frizelle FA: Management of diverticulitis. BMJ 2006;3327536: 271-275.

138 Mizuki A, Nagata H, Tatemichi M, Kaneda $\mathrm{S}$, Tsukada N, Ishii $\mathrm{H}$, et al: The out-patient management of patients with acute mild-tomoderate colonic diverticulitis. Aliment Pharmacol Ther 2005;217:889-897.

139 King WC, Shuaib W, Vijayasarathi A, Fajardo CG, Cabrera WE, Costa JL: Benefits of sonography in diagnosing suspected uncomplicated acute diverticulitis. J Ultrasound Med 2015;341:53-58.

140 Stefansson T, Ekbom A, Sparen P, Pahlman $\mathrm{L}$ : Increased risk of left sided colon cancer in patients with diverticular disease. Gut 1993; 344:499-502.

141 Kieff BJ, Eckert GJ, Imperiale TF: Is diverticulosis associated with colorectal neoplasia? A cross-sectional colonoscopic study. Am J Gastroenterol 2004;9910:2007-2011.

142 Soran A, Harlak A, Wilson JW, Nesbitt L, Lembersky BC, Wienad HS, et al: Diverticu- lar disease in patients with colon cancer: subgroup analysis of national surgical adjuvant breast and bowel project protocol C-06. Clin Colorectal Cancer 2006;62:140145

143 Choi YH, Koh SJ, Kim JW, Kim BG, Lee KL, Im JP, et al: Do we need colonoscopy following acute diverticulitis detected on computed tomography to exclude colorectal malignancy? Dig Dis Sci 2014;599:2236-2242.

144 Weizman AV, Nguyen GC: Diverticular disease: epidemiology and management. Can J Gastroenterol 2011;257:385-389.

145 Stollman N, Raskin JB: Diverticular disease of the colon. Lancet 2004;3639409:631-639.

146 Brochmann ND, Schultz JK, Jakobsen GS Oresland T: Management of acute uncomplicated diverticulitis without antibiotics: a single-centre cohort study. Colorectal Dis 2016;1811:1101-1107.

147 Chabok A, Tarnberg M, Smedh K, Pahlman L, Nilsson LE, Lindberg C, et al: Prevalence of fecal carriage of antibiotic-resistant bacteria in patients with acute surgical abdominal infections. Scand J Gastroenterol 2010 4510:1203-1210.

148 Chabok A, Pahlman L, Hjern F, Haapaniemi S, Smedh K; AVOD Study Group: Randomized clinical trial of antibiotics in acute uncomplicated diverticulitis. Br J Surg 2012 994:532-539.

149 Isacson D, Andreasson K, Nikberg M, Smedh K, Chabok A: No antibiotics in acute uncomplicated diverticulitis: does it work? Scand J Gastroenterol 2014;4912:14411446.

150 Isacson D, Thorisson A, Andreasson K, Nikberg M, Smedh K, Chabok A: Outpatient, non-antibiotic management in acute uncomplicated diverticulitis: a prospective study. Int J Colorectal Dis 2015;309:12291234.

151 Daniels L, Unlu C, de Korte N, van Dieren S, Stockmann HB, Vrouenraets BC, et al: Randomized clinical trial of observational versus antibiotic treatment for a first episode of CT-proven uncomplicated acute diverticulitis. Br J Surg 2017;1041:52-61.

152 Andersen JC, Bundgaard L, Elbrond H, Laurberg S, Walker LR, Stovring J, et al: Danish national guidelines for treatment of diverticular disease. Dan Med J 2012;595: C4453.

153 Andeweg CS, Mulder IM, Felt-Bersma RJ, Verbon A, van der Wilt GJ, van Goor H, et al: Guidelines of diagnostics and treatment of acute left-sided colonic diverticulitis. Dig Surg 2013;30:278-292.

154 Longo SA, Moore RC, Canzoneri BJ, Robichaux A: Gastrointestinal conditions during pregnancy. Clin Colon Rectal Surg 2010; 232:80-89.

155 Hwang SS, Cannom RR, Abbas MA, Etzioni D: Diverticulitis in transplant patients and patients on chronic corticosteroid therapy: a systematic review. Dis Colon Rectum 2010;5312:1699-1707. 
156 Binda GA, Cuomo R, Laghi A, Nascimbeni $\mathrm{R}$, Serventi A, Bellini D, et al: Practice parameters for the treatment of colonic diverticular disease: Italian Society of Colon and Rectal Surgery (SICCR) guidelines. Tech Coloproctol 2015;1910:615-626.

157 Regenbogen SE, Hardiman KM, Hendren S, Morris AM: Surgery for diverticulitis in the 21st century: a systematic review. JAMA Surg 2014;1493:292-303.

158 Katsuno G, Fukunaga M, Nagakari K, Yoshikawa S: Laparoscopic one-stage resection of right and left colon complicated diverticulitis equivalent to Hinchey stage I-II. Surg Today 2011;415:647-654.

159 Oberkofler CE, Rickenbacher A, Raptis DA, Lehmann K, Villiger P, Buchli C, et al: A multicenter randomized clinical trial of primary anastomosis or Hartmann's procedure for perforated left colonic diverticulitis with purulent or fecal peritonitis. Ann Surg 2012;256:819-826.

160 Cirocchi R, Trastulli S, Desiderio J, Listorti C, Boselli C, Parisi A, et al: Treatment of Hinchey stage III-IV diverticulitis: a systematic review and meta-analysis. Int J Colorectal Dis 2013;284:447-457.

161 Feingold D, Steele SR, Lee S, Kaiser A, Boushey R, Buie WD, et al: Practice parameters for the treatment of sigmoid diverticulitis. Dis Colon Rectum 2014;573:284-294.

162 Brandt D, Gervaz P, Durmishi Y, Platon A, Morel P, Poletti PA: Percutaneous CT scanguided drainage vs. antibiotherapy alone for Hinchey II diverticulitis: a case-control study. Dis Colon Rectum 2006;4910:15331538.

163 Elagili F, Stocchi L, Ozuner G, Kiran RP: Antibiotics alone instead of percutaneous drainage as initial treatment of large diverticular abscess. Tech Coloproctol 2015;192: 97-103.

164 Siewert B, Tye G, Kruskal J, Sosna J, Opelka F, Raptopoulos V, et al: Impact of CT-guided drainage in the treatment of diverticular abscesses: size matters. AJR Am J Roentgenol 2006; 1863:680-686.
165 Jacobs DO: Clinical practice. Diverticulitis. N Engl J Med 2007;35720:2057-2066.

166 Aydin HN, Tekkis PP, Remzi FH, Constantinides V, Fazio VW: Evaluation of the risk of a nonrestorative resection for the treatment of diverticular disease: the Cleveland Clinic diverticular disease propensity score. Dis Colon Rectum 2006;495:629-639.

167 Lamb MN, Kaiser AM. Elective resection versus observation after nonoperative management of complicated diverticulitis with abscess: a systematic review and meta-analysis. Dis Colon Rectum 2014;5712:14301440.

168 Cirocchi R, Arezzo A, Renzi C, Cochetti G, D'Andrea V, Fingerhut A, et al: Is laparoscopic surgery the best treatment in fistulas complicating diverticular disease of the sigmoid colon? A systematic review. Int J Surg 2015;24 (Pt A):95-100.

169 Cirocchi R, Cochetti G, Randolph J, Listorti C, Castellani E, Renzi C, et al: Laparoscopic treatment of colovesical fistulas due to complicated colonic diverticular disease: a systematic review. Tech Coloproctol 2014; 1810:873-885.

170 Tomizawa K, Hanaoka Y, Toda S, Moriyama J, Matoba S, Kuroyanagi H, et al: Clinical study of colovesical fistula due to sigmoid colon diverticulitis treated laparoscopically. J Jpn Soc Endosc Surg 2012;17:753-759 (in Japanese).

171 Klarenbeek BR, Samuels M, van der Wal MA, van der Peet DL, Meijerink WJ, Cuesta MA: Indications for elective sigmoid resection in diverticular disease. Ann Surg 2010; 2514:670-674.

172 Parks TG: Natural history of diverticular disease of the colon. A review of 521 cases. Br Med J 1969;45684:639-642.

173 Broderick-Villa G, Burchette RJ, Collins JC, Abbas MA, Haigh PI: Hospitalization for acute diverticulitis does not mandate routine elective colectomy. Arch Surg 2005;140: 576-581.

174 Buchs NC, Mortensen NJ, Ris F, Morel P, Gervaz P: Natural history of uncomplicated sigmoid diverticulitis. World J Gastrointest Surg 2015;711:313-318.

175 Bharucha AE, Parthasarathy G, Ditah I, Fletcher JG, Ewelukwa O, Pendlimari R, et al: Temporal trends in the incidence and natural history of diverticulitis: a population-based study. Am J Gastroenterol 2015; 11011:1589-1596.

176 Hupfeld L, Burcharth J, Pommergaard HC, Rosenberg J: Risk factors for recurrence after acute colonic diverticulitis: a systematic review. Int J Colorectal Dis 2017;325:611-622.

177 Buchwald P, Dixon L, Wakeman CJ, Eglinton TW, Frizelle FA: Hinchey I and II diverticular abscesses: long-term outcome of conservative treatment. ANZ J Surg 2017; 8712:1011-1014.

178 Elagili F, Stocchi L, Ozuner G, Dietz DW, Kiran RP: Outcomes of percutaneous drainage without surgery for patients with diverticular abscess. Dis Colon Rectum 2014;573: 331-336.

179 Hyland JM, Taylor I: Does a high fibre diet prevent the complications of diverticular disease? Br J Surg 1980;672:77-79.

180 Tursi A, Brandimarte G, Daffina R: Longterm treatment with mesalazine and rifaximin versus rifaximin alone for patients with recurrent attacks of acute diverticulitis of colon. Dig Liver Dis 2002;347:510-515.

181 Dughera L, Serra AM, Battaglia E, Tibaudi D, Navino M, Emanuelli G: Acute recurrent diverticulitis is prevented by oral administration of a polybacterial lysate suspension. Minerva Gastroenterol Dietol 2004;502: 149-153.

182 Tursi A, Brandimarte G, Giorgetti GM, Elisei W, Aiello F: Balsalazide and/or high-potency probiotic mixture (VSL\#3) in maintaining remission after attack of acute, uncomplicated diverticulitis of the colon. Int J Colorectal Dis 2007;229:1103-1108.

183 D'Inca R, Pomerri F, Vettorato MG, Dal Pont E, Di Leo V, Ferronato A, et al: Interaction between rifaximin and dietary fibre in patients with diverticular disease. Aliment Pharmacol Ther 2007;257:771-779. 